\title{
Open-inquiry driven overcoming of epistemological difficulties in engineering undergraduates: A case study in the context of thermal science
}

\author{
Nicola Pizzolato, ${ }^{1, *}$ Claudio Fazio, ${ }^{1}$ Rosa Maria Sperandeo Mineo, ${ }^{1}$ \\ and Dominique Persano Adorno \\ ${ }^{1}$ UOP-PERG (University of Palermo-Physics Education Research Group), \\ Università di Palermo, Palermo 90128, Italy \\ ${ }^{2}$ GIP (Group of Interdisciplinary Physics), Dipartimento di Fisica e Chimica, \\ Università di Palermo, Palermo 90128, Italy \\ (Received 15 August 2013; published 18 February 2014)
}

\begin{abstract}
This paper addresses the efficacy of an open-inquiry approach that allows students to build on traditionally received knowledge. A sample of thirty engineering undergraduates, having already attended traditional university physics instruction, was selected for this study. The students were involved in a sixweek long learning experience of open-inquiry research activities within the highly motivating context of developing a thermodynamically efficient space base on Mars. They designed and carried out their own scientific investigations, which involved gathering information, collecting and analyzing data, providing explanations, and sharing results. A questionnaire containing fifteen open-ended real-world problems in thermal science was administered to the students both prior to and after all activities, with the aim of investigating the nature of their difficulties in problem solving. Students' answers were classified into three epistemological profiles and a prepost instruction comparison was carried out, using methods of statistical implicative analysis. The students obtained significant benefits from their open-inquiry experiences, in terms of the strengthening of their practical and reasoning abilities, by proficiently applying the learned concepts to face and solve real-world problem situations.
\end{abstract}

DOI: 10.1103/PhysRevSTPER.10.010107

PACS numbers: 01.55.+b, 01.40.gb, 01.40.G-

\section{INTRODUCTION}

The practice of today's scientists and engineers is often exerted within interdisciplinary contexts, placed at the intersections of different fields and applications [1,2]. Creativity, particularly in design processes and data analysis, dynamism, flexibility, and innovation are the mainly required professional qualities. Graduates should demonstrate the ability to hold specialist-discipline knowledge, abilities to solve practical problems, competences on using mathematical, scientific, and technological tools to analyze and interpret data, communication skills, and the mind-set for undertaking lifelong learning [3,4]. The development of all these competences needs an effective science and engineering instruction, which would be able to drive students towards a deeper understanding of disciplinary fundamental concepts and, at the same time, to strengthen their reasoning skills and transversal abilities (see [5] and references therein).

An effective learning of thermal science has always been a particularly arduous objective to be pursued, because of

*nicola.pizzolato@unipa.it

Published by the American Physical Society under the terms of the Creative Commons Attribution 3.0 License. Further distribution of this work must maintain attribution to the author(s) and the published article's title, journal citation, and DOI. the difficulties, faced by students at any level of education, to understand everyday experiences governed by the intrinsic properties of matter [6-8]. On the other hand, it is well established that learners' difficulties in problem solving may also be due to their views of science and/or inappropriate use of epistemological resources [9-15].

It is widely recognized that both conceptual and epistemological difficulties on problem solving could be overcome by introducing the students to the practice of scientific reasoning and, in this view, a science education carried out by promoting the development of the process of inquiry-learning through questioning-has been long considered a viable solution [16-18]. In fact, an inquirybased teaching environment is today considered the natural framework for developing opportunities for learning science in terms of an active construction of meaningful knowledge [19-22].

This study is significant in that it is one of the first to explore quantitative relationships between inquiry and student epistemologies - beliefs students have about how scientific knowledge is produced. In this work, we have addressed the problem of developing an effective-from the above-explained point of view-strategy of instruction for science or engineering students, involved in the study of the physics underlying the complex world of thermal phenomena. We invited a group of engineering undergraduates, randomly selected among those who already 
attended physics lectures, to experience an open-inquiry (OI) based learning environment. Students were involved in a highly challenging project, aimed at the practical experimentation of ideas within a well-defined research context, regarding the design of a thermodynamically efficient space base on Mars. By working in small groups, students designed and carried out their own research activities, collected and analyzed data, and shared their results.

Students' processes of scientific reasoning connected with their epistemological beliefs on how to answer science questions have been probed by using a questionnaire with common life open-ended problems on thermal science, which was administered prior to and after the OI-based instruction. Students' answers were classified into three epistemological profiles, characterized by different levels of ability to face and solve real-world problems by meaningfully applying the background of studied laws and theories. A pre-post-instruction comparative study was performed by means of statistical implicative analysis [23]. We have found that engineering undergraduates, traditionally instructed, experience several difficulties on problem solving, due to their epistemological stances. The OI-based activities performed by our students promoted their scientific reasoning, eliciting the meaning of the conceptual knowledge they already held. Within the theoretical framework of epistemological variability [24-26], we also argue that an OI-based instructional environment may provide students with appropriate cognitive resources to promote more productive epistemological stances, resulting in higher numbers of students solving problems successfully.

In the following section we introduce the rationale of our research study, by providing a background of the general framework for OI-based instruction and an outline of the theory of epistemological variability and its context dependence. Then we present the research question addressed in this paper and a detailed description of our project. The procedure to collect and analyze the data and the results are reported in the subsequent sections and discussed in the summary and conclusions section. Final comments about the advantages and limits of OI-based teaching strategies for physics education of science or engineering students, and suggestions for further developments, are provided at the end of the paper.

\section{THE RESEARCH STUDY}

\section{A. Theoretical background: Inquiry-based instruction and epistemology of science}

Inquiry-based science education is considered to be an important current trend in science education reform. In the European context, numerous inquiry-based science and mathematics projects [27] aim at promoting the development of inquiry-based science teaching methods and support the effective implementation of inquiry practices through the equally important contribution of both science content knowledge and pedagogical process knowledge
$[19,28]$. Very recent updates of the American standards of science education strongly encourage the development of instructional environments focused on the engagement in the practices of design, being convinced that this latter is equally important in the process of learning science, as the engagement in the practice of science [21,29].

The teaching strategies involved in inquiry approaches are grounded on the viewpoint that students are active thinkers, who construct their own understanding from interactions with phenomena, the environment, and other individuals. In inquiry-based learning, the students are engaged in identifying scientifically oriented questions, planning investigations, collecting data and evidences in laboratory and/or real life situations, building descriptions and explanation models, sharing their findings, and eventually addressing new questions that arise. Depending on the amount of information and support provided by the teachers, the learners may be involved in a structured or guided inquiry or OI [30-32]. Generally, in structured inquiry the questions and procedures are provided by the teacher, and students generate their own explanations, supported by the evidence they have collected. In guided inquiry the teacher provides the students with only the research questions, and the students design the procedures to find reasonable answers and/or test the resulting explanations. In OI-based instruction, the teacher takes the delicate role of defining the context for inquiry, stimulating the students to derive their own questions, design and carry out independent investigations, construct coherent explanations, and share their findings. This level of inquiry requires the highest capacity of scientific reasoning.

A model of sequencing learning experiences is represented by the 5 E model [33] that leads students through five phases of learning: engage, explore, explain, elaborate, and evaluate. By synthesizing, the different phases can be described as follows: (1) engagement involves the setting of the learning environment in a way that stimulates interest and generates curiosity in the topic under study; (2) exploration is the beginning of student engagement in inquiry, by searching for information, raising questions, developing hypotheses to test; (3) explanation involves the process of data acquisition and evidenceprocessing techniques for the individual groups or entire class (depending on the nature of investigation) from the information collected during the exploration; (4) elaboration is the state in which acquired information is discussed with peers and the teacher by acquiring the extension of concepts to new situations and possible generalizations; (5) evaluation involves students' capacity to make judgments, analyses, and evaluations of their work, also in comparison with the work of their colleagues.

Many efforts have been carried out in order to introduce inquiry-based teaching approaches in K-12 grades of instruction [34-38]. A recent study [39] has shown positive shifts in the conceptual understanding and problem-solving categories of the Colorado Learning Attitudes about 
Science Survey (CLASS) by preservice and in-service teachers experiencing the Physics by Inquiry curriculum [40]. At the university level, the pedagogical effectiveness of incorporating guided inquiry-based activities, concerning the topic of heat transfer, has been observed in courses for chemical engineering undergraduates, who achieved higher overall scores on answering a postinstruction concept inventory [41]. Concerning the interaction between science concept learning and the using of inquiry activities, it is relevant to note that some researchers $[42,43]$, although utterly convinced that physics education must include elements of real, genuine investigation for students to experience, show some criticism concerning two aspects about inquiry-based teaching approaches. The first one regards the impossibility of replicating the scientific process of inquiry in the frame of a typical science lesson [42]. The second one is about the difficulty to use inquiry-based approaches to develop new scientific concepts [43]. Some educational researchers consider the guided inquiry as the most appropriate approach for developing an effective understanding of critical concepts and also a deeper awareness of the nature of science [39], avoiding possible motivational effects that could be observed during OI and affect the successful completion of the learning process $[44,45]$.

Moreover, Berg et al. [46] compared students' outcomes from an OI-based activity with those obtained in the context of a structured laboratory concerning the same experiment, finding the most positive results in students following the OI approach. Other studies assert that experiencing OI-based activities make it possible to achieve higher levels of critical thinking skills and understanding the nature of science [47,48]. Zion et al. [49] conducted a long-term 3 -year action research concerning the application of an OI approach to the study of biology. They considered the OI-based learning a dynamic process grounded on a continuous and renewed thinking activity, involving flexibility, judgment, and contemplation, as part of the changes that occur in the course of inquiry. In a subsequent paper, Sadeh and Zion [50] compared the mean scores achieved by 12th grade students, experiencing guided inquiry, with those obtained by following an OI-based learning approach. They measured a significant difference between the scores achieved by the two groups. In particular, the OI outperformed guided inquiry in terms of "changes occurring during inquiry" and "procedural understanding," regarding affective aspects and the perspectives of critical and reflective thinking about the process.

In summary, an instruction based on structured or guided inquiry seems to be effective on repairing misconceptions [41], but it is not yet clearly established its usefulness to produce functional epistemological perceptions of science [51]. On the other hand, students involved in OI learning experiences, having the purest opportunity to act like scientists, would gain the awareness of the process of scientific inquiry and a deeper view of the nature of science
[52-56]. However, this latter approach, requiring the greatest cognitive demand from students in terms of scientific reasoning, may induce feelings of inadequacy or frustration, due, for example, to achieving of undesirable results, and could not bring about an effective understanding of the concepts $[44,45]$. It seems that both approaches, individually considered, could not result in being effective enough, suggesting integrated teaching or learning strategies must be taken into account.

A second major area of recent literature on the influence of epistemologies on science learning has been informational for our study. In fact, many researchers have become increasingly interested in the interplay between science conceptual learning and other cognitive factors, such as personal learning frameworks [57], learning beliefs, and science epistemologies [58-60]. It is relevant to note that when we talk about student epistemologies we are not talking about their broad general beliefs about the nature of science. Rather, we are referring to what Bing and Redish [61] call functional epistemologies or personal epistemologies-i.e., "how students decide they know in a particular context in a particular moment" or "how they decide what knowledge is relevant to bring to bear in solving a particular problem" or "what counts as valid proof." Here, we mainly analyze the influence of students' epistemological ideas on their approach to problem solving and the construction of their own scientific knowledge. It has been shown that students' epistemological beliefs about science play a significant role on their ability to solve a problem [61-64]. Novice learners usually consider scientific knowledge as a set of well-established theories and/or facts, supported by direct or indirect experimental validations. In students' naive perceptions, physics laws, being expressed in terms of mathematical equations and giving rise to the possibility of making precise predictions, are considered neither more nor less than computational tools for problem solving $[65,66]$. Students may achieve a distorted view of a physics law, considered exclusively as a mathematical entity to be applied within a specific problematic context, and completely miss its expression in terms of meaningful concepts $[60,67,68]$. This epistemological stance is very strong and widespread, because it is grounded on the traditional view of science as a source of unfailing knowledge, capable of accurate quantitative expressions and rigorous methods of testing hypotheses.

Our guiding idea is that OI-based teaching strategies, promoting an involvement in activities similar to those carried out by scientists, should provide students with the opportunity to deepen their understanding on how scientific knowledge is produced in real research contexts. Moreover, the way inquiry is implemented in the classroom has direct consequences upon the epistemological ideas that students might bring to bear on their work and on how the learning 
activity may change their perspective on scientific knowledge [69]. These "practical epistemologies" can be quite different from their perceptions of formal science and significantly affect the student's ability to step forward on finding a solution to a problem.

In order to design an effective inquiry-based instruction, it is not sufficient to know what students know about a topic. One must consider the opportunity to produce a fruitful change on students' epistemologies of science, which are not globally robust beliefs that drives students' learning and problem-solving, but rather context-dependent locally coherent views whose stability depends both on external inputs and on students' internal conceptions and emotional states $[14,15,70,71]$.

\section{B. Rationale and research question}

In many university courses, physics concepts are still taught by following a traditional approach that aims at transferring the contents and trains the students to solve problems similar to those they will encounter at the final examination. Sometimes, at the end of the lecture cycle, students are also introduced to some laboratory activities, which are often proposed as a mere confirmation of the studied physics laws. Many research studies show that this approach is hardly successful because it contains an intrinsic incongruity due to the fact that the problemsolving ability, which is almost universally accepted as an evaluation parameter for the students' understanding of concepts, cannot be developed by simply transmitting the rules of the game, i.e., the physics laws governing the natural phenomena, and asking the students to apply them.

With regard to students' understanding of thermal concepts, many researchers have indicated that students can get easily confused primarily because of the language gap between the scientific definition and everyday terminology for heat, temperature, and energy [72-75]. Moreover, concepts like specific heat capacity, conductivity, or rate of heat energy transfer are sometimes not differentiated in students' minds and not adequately used in their explanations of everyday phenomena related to thermal concepts $[6,7,76]$. In thermal science, students often have to deal with complex situations, involving emergent processes, such those occurring in systems of randomly interacting constituents. The lack of a relevant mental framework for the understanding of a complex event has suggested the development of schema training strategies [77,78], aimed at helping students to create appropriate mental frames in which to accommodate important science concepts.

Very recently, two powerful instruments, namely the Thermal and Transport Science Concept Inventory (TTCI) by Miller et al. [78] and the Heat and Energy Concept Inventory (HECI) by Prince et al. [79], have been finalized to assess the presence of persistent misconceptions in undergraduates studying thermal science. Both researches have confirmed the presence of robust misconceptions in engineering students, even after having attended a semester or more of traditional instruction on thermal science.

Our study concerns the implementation of an OI-based learning environment, in which already-instructed students are involved in a high challenging researchlike work, oriented towards the application of the physics concepts they should have learned in their previous traditional courses on thermal science. To the best of our knowledge, an OI-based approach has never been adopted in the education of engineering undergraduates in the context of the study of thermal phenomena. Our general objective is to investigate (a) the presence of epistemological difficulties preventing the effective application of the studied theories to the resolution of problematic situations, which could be encountered in everyday experience and phenomena; (b) the efficacy of an OI-based approach to help engineering students overcome such difficulties by strengthening their abilities to carry out scientific descriptions and explanations of thermal phenomena.

The main research question addressed in this paper is the following:

How effective is an OI-based learning environment to provide epistemological resources useful to help engineering undergraduates to improve their ability to solve problems on common life thermal phenomena?

Our research has been developed in different phases. First, we constructed and validated an instrument having the form of an open-ended questionnaire, with the aim of collecting information about the typical difficulties encountered by young undergraduates. In a subsequent phase, we selected a sample of engineering students and involved them in a pilot project concerning the experimentation of an appropriate OI-based learning environment. The students answered the questionnaire before the beginning of the learning activities (pretest) and again at the end of the learning trail (posttest). The method of implicative statistical analysis has been applied to quantitatively estimate both similarities and implications between different students' answering strategies.

\section{The sample}

Our sample consists of thirty mechanical engineering undergraduates ( 24 males and 6 females, aged between 20 and 22 years) attending the second or third year of the traditional curriculum of engineering instruction. In order to gain access to the academic courses, all engineering students passed a multiple-choice test on general knowledge and logic questions with scores greater than $6 / 10$. Our participants were randomly selected between all students having (i) passed the access test with a score greater than $7 / 10$ and (ii) already attended the basic physics courses and passed the related examinations. In particular, the knowledge background of the selected students included a specific theoretical introduction to the concepts of thermal 
science and a more technical instruction on applied thermodynamics. The average scores achieved by students in these subjects are distributed among three levels: lowachieving (6 students with scores in the range: 18-22/30), medium-achieving (14 students with scores in the range: 23-26/30), high-achieving (10 students with scores in the range: $27-30 / 30$ ). The students' outcomes to their curricular examinations are mainly distributed around the medium-high level, with a global average not far from that recorded in the full population of local engineering students. All selected students accepted to join the project, after a brief presentation made by the authors at the faculty council for mechanical engineering, where the general objective of the project was illustrated. Students involved in this study have never had specific instruction about the process of scientific inquiry and never participated to other inquiry-based learning programs.

\section{Activity description: Mission to Mars}

Our decision to activate a pilot project on the topic of thermal physics has been induced mainly by the conviction that the management of many science or engineering problems requires an effective knowledge of the basic concepts of this branch of science. As a consequence, our OI-based learning environment has been designed to meet the students' necessities to achieve a more meaningful understanding of taught physics concepts and improve their abilities to solve common life problems they never encountered before.

The proposed activities involved the students in a highly challenging learning environment, starting from the problem of projecting a thermodynamically efficient space base on Mars. The project was developed across five main phases. During all the stages, the students' activities were supported by two educators having more than fifteen years of expertise in the field of scientific research and on teaching physics at both high school and university levels.

In the first phase (engagement), the educators presented the project to the students, providing a brief description of the context in which their work would have been developed and the motivation for an active participation. The students were invited to take part to an experimental project regarding the best materials to use in the construction and, more specifically, the best design strategies to practice in order to collect as much thermal energy as possible during the Martian day, and avoid heat dispersion during the cold night. Students were asked to work in groups of 5 participants (4 males and 1 female for each group) and to perform scientific investigations devoted to the design, realization, and testing of smart devices, having physical characteristics able to maximize the capture and storage of thermal energy from the Sun and/or systems with high insulating efficiency. Group members were chosen by the educators on the basis of student scores on academic physics courses, in order to have the six groups all composed of heterogeneous profiles. All groups of students were invited to carry out their own experimental work, by taking into account the physics underlying the process of thermal energy exchange by conduction, convection, and radiation. During this phase, the interaction between educators and students was mainly aimed at clarifying the reciprocal roles, with the first ones discussing with the students what they were expected to do within the IO learning environment. Before the beginning of all activities, the students answered a questionnaire.

Students dedicated the second phase of the project (exploration) to acquiring information and planning their activities. In this phase, the students were introduced to our laboratory and stimulated to explore the measurement facilities and available materials in order to design their own experiences. They were also informed about the opportunity to use all campus libraries and Internet resources to gather appropriate literature. Independently of their membership to a given group, the students followed two different paths of exploration. Some of them started the activity by searching the Web to collect information about the physical characteristics of the Martian atmosphere, real weather condition on Mars (for example, the presence of winds), thermal properties of common insulation materials, and solar passive systems. Other students ignored the computers and prepared an inventory of all materials in the lab they could have used to carry out their experiments, such as polystyrene boxes, aluminum sheets and pipes, plywood, several plastic materials, and glasses. These two different explorative approaches were observed in all groups of students. The educators asked the students to organize in advance their work and to write a document containing the details of all the experiments that they were planning to carry out. However, the educators always left the students free to plan the experiments by following their own procedure and even to bring in the lab homemade resources, or to move outside the department building, if necessary, with the only request of always taking notes of their activities. The educators never suggested which experiment would be better to carry out in order to answer the students' research questions, nor did they comment on the procedures adopted by students during their measurements. In this phase the role of the educators was mainly that of a laboratory guide providing, on request, technical support and practical advice on the feasibility of planned experiments.

In the third phase of the project (explanation), the students carried out their research investigations, designed on the basis of their hypotheses pointed out during the explorative phase. They dedicated about thirty hours to completing their laboratory activities by collecting, processing, and analyzing data in the most independent way they felt confident to do it. In particular, each group developed one or more devices aimed at testing some relevant physical characteristics of their system (see pictures in Fig. 1). A group assembled a parabolic mirror with 




FIG. 1 (color online). Pictures of specific devices assembled by the students during the OI experience: a parabolic mirror (a), a scale model of Trombe-Michel wall (b), insulating systems (c)-(f), the greenhouse effect (g), a modeled underground hypothetical Martian base (h).

an aluminum pipe on its focus to warm a liquid flowing inside [Fig. 1(a)], another group built a scale model of Trombe-Michel wall filled with sodium-polyacrylate gel [Fig. 1(b)], others tested several insulating systems [Figs. 1(c)-1(f)] and the relevance of the greenhouse effect [Fig. 1(g)]. A group studied the insulation properties of a modeled underground hypothetical Martian base [Fig. 1(h)]. In order to collect their data, the students mainly used surface temperature sensors interfaced to a computer for real time measurements, but also infrared thermometers and a spectrometer to evaluate the transmissivity of plastic sheets or glasses. Students used logbooks to note the followed procedures, the difficulties encountered throughout the activity, and the changes they made during the inquiry process. The educators supported the students by acting as facilitators of their experimental activities, for example providing tips on software use for a better data visualization, but never correcting students' mistakes or improper procedures to collect the data. Generally, they never explicitly answered students' questions, but raised more focused questions, in order to facilitate the linking between student reasoning hypotheses and their experimental practices. In this phase the educators often asked the students to question themselves about the scientific motivation of their activities and the obtained results, stimulating the students to reason on the validity of their experiments.

In the subsequent phase of the project, the students presented the most significant findings obtained as a result of their experimental work, by writing a final scientific report (elaboration). Indeed, the students shared their ideas and preliminary results with the other participants also during the previous phases of the project. However, at the end of all activities, the educators formally invited the students to present the results of their scientific investigations by means of oral communications. In that context, the educators suggested that the students search the Web for useful indications on how to prepare scientific reports and presentations. They did not assist the students in the production process of their presentations, but saw only the final products. They simply asked the students to give a logical sequence of the results shown in their slides, providing reasoned comments and conclusions.

A final phase (evaluation) has been devoted to a classroom discussion aimed at comparing and contrasting the results obtained by different groups of students. Here, the educators assumed the role of moderators in student discussions, sometimes by rephrasing unclear discourses in order to focus student attention on a specific concept or by triggering further questions, highlighting critical points on the proposed scientific explanations of their findings. The educators' interventions were mainly aimed at stimulating the students' critical thinking, by asking the students how they would have carried out the same experiment of a different working group, or have analyzed their data, to better address the investigated problem and strengthen their conclusions. At the end of all activities, the same questionnaire answered at the beginning of the project was readministered.

\section{RESEARCH METHOD}

A single sample of students is used in this research, within a pre-post-activity design. The rationale of this choice is based on the specific characteristic of our sample, which consists of students who have already completed their curricular physics education at the university level and have never been involved in inquiry-based learning paths before. In this respect, the proposed experience represents an additional activity, explicitly based only on OI. Before the beginning of the project, students were not informed 
about the duty to answer to the same questionnaire both prior to and after instruction, so they answered the test during the first introductory meeting, by considering the questionnaire only as an instrument for educators to assess their initial competences. During the learning activities none of the situations proposed in the questionnaire items have been explicitly analyzed. So, we can consider the modifications in the students' postinstruction answers as mainly being due to their personal revisions of the involved situations, consequent to the proposed learning activities. Moreover, the students' answers to the questionnaire were all evaluated by the educators only at the end of the project, in order to avoid possible influences on their teaching activity.

All the steps of students' inquiry activities have been recorded directly by students in a workbook (containing planning documents, logbooks of experiments, and scientific reports) that students presented at the end of the OI experience. Moreover, the entire activity in the laboratory was video recorded by using one camera per working group. We collected a huge amount of different data and the process of analysis of all this information is still in progress, on the basis of an in-context search for keywords or phrases and specific aspects of the students' answers that could give evidence of specific cognitive processes.

In this paper, we report the results of a detailed analysis of preinstruction answers to the questionnaire and a comparison with postinstruction outcomes. The methods of statistical implicative analysis, presented below in Sec. III B, were applied to quantitatively estimate both similarities and implications between different students' answering strategies.

\section{A. Development and validation of the questionnaire}

The questionnaire implementation was carried out by following several stages of development and validation. Initially, we carefully examined the questionnaires and tests reported in literature, aimed at assessing the student's ability to fully understand thermal concepts and effectively face problematic situations. In particular, we analyzed two recent concept inventories available on the topic of thermal science, namely the TTCI and the HECI [78,79]. Both represent a powerful instrument to investigate students' misconceptions and may provide quantitative evidence of the students' understanding of foremost concepts. However, as any closed-answer questionnaire, a concept inventory provides the learner with a selection of possible answers to a question. Even not considering this as one possible source of bias in students' performance, it certainly affects the students' way to approach the resolution of a problem. Given our specific research question, we developed an instrument aimed at explicitly investigating the difficulties experienced by engineering students involved into the resolution of common life problems concerning thermal phenomena.
In order to further explore this point and collect information about the typical difficulties encountered by young undergraduates in their learning of thermal science, we informally interviewed twelve faculty professors teaching physics in engineering. Faculty members first admitted that the lecture-based teaching approach, commonly adopted because of the high number of students attending the lecture, is not the most appropriate one to receive feedback from the students about the difficulties experienced during the course. They usually gather some information only at the end of the lecture cycle, through the analysis of the students' outcomes at the final examination, with few exceptions of those who administer intermediate control tests. They also realized that the evaluation of learning difficulties by simply considering the scores achieved by the students on the resolution of standard problems, that most professors usually treat during the lesson, is not effective. In their analysis, faculty members identified several concepts whose full comprehension by engineering students appeared to play a crucial role. They decided to independently rank those concepts by classifying them within five levels of increasing difficulty. With a percentage of accordance of about $97 \%$, faculty members agreed that the students usually experience the greatest difficulties when they face new problematic situations where, in particular, the concepts of heat capacity and thermal energy transfer are involved. Faculty members' comments and suggestions were taken into account to prepare a draft version of the questionnaire with fifteen problems, reporting practical experiments or simple reallife situations where the students were asked to make their predictions and provide meaningful explanations.

In the construction of the questionnaire we aimed at evaluating student reasoning and abilities on pattern recognition, within arrangements of concepts, that have been considered the two main factors affecting a successful approach to the resolution of problematic situations [80]. In this view, our assessment instrument was imagined also as a test to measure the extent to which students face common life problems by showing a scientific thinking approach. This essentially means a great attention for all the measurable quantities involved in the process and the finding of reasonable connections between the observed phenomenon and an explanatory model, conceived within a continuously evolving matrix of concepts.

In order to assess such ability in students' knowledge of thermal science, we decided to structure the questionnaire with open-answer problems, having with this format the advantage of collecting the answers that learners give spontaneously, avoiding the bias that may result from suggesting responses to individuals. The majority of the questions, however, were arranged within a multiple-choice structure, containing a mandatory open field to be filled with an exhaustive motivation of the selected choice. In this way, the questionnaire maintained the appearance of a 
closed-ended test, which is generally faced by the students with a higher level of confidence and more positive attitudes. The analysis of the outcomes from open-ended questions usually needs an extensive coding of the answers; in our case we have performed this action first during the process of questionnaire validation, which is described below, and, second, with the answers provided by the students selected for this study (see Sec. IV).

The validation process of the questionnaire was conducted in three separate phases, each time evaluating the appropriateness, meaningfulness, and usefulness of the specific inferences from the test answers. In the first stage, an a priori analysis of the questionnaire validity was carried out: each author, independently from the others, tried to hypothesize all possible answers that a student could supply when facing the problematic situations described in the questions. This analysis was conducted independently of the observation (hence the term a priori), in order to provide a reference point for the subsequent study of the actual students' responses to the questionnaire items (a posteriori data). According to Brousseau [81], a search for possible student answers and/or answering strategies can be very useful to highlight weak points in the questions, and modify them before administering the questionnaire. The answer lists were compared and discussed by all the researchers, in a form of content validation [82] and, as a result of this interaction, a revised version of the questionnaire was developed.

In a subsequent phase, a pilot validation was carried out by administering the questionnaire to a group of 45 high school students with no previous experiences on inquirybased learning and having followed a science curriculum similar to those attended by our engineering undergraduates in their preuniversity school career. Students' answers were analyzed by the researchers and compared with those they hypothesized during the a priori analysis. It emerged that some of the hypothesized answers were not given by the students and, as a contrast, some others, unforeseen during the a priori analysis, were found. The list of a priori-collected answers was updated by including the a posteriori (real students) responses not previously considered. Even if the background on thermal physics was only partially comparable with that of our engineering students, who already attended university level courses, the answers provided by the younger learners were very useful also to highlight residual problems in the questions, mostly due to unclear or ambiguous terminology, and to further revise the questionnaire.

In the last phase of the validation process, we finally administered the questionnaire to a sample of twelve engineering students, in order to test our pilot validation on learners having received the same traditional physics instruction of our research sample, but not being part of it. A focus group was conducted with these students in order to clarify the meaning of some unclear answers they provided and get to the final version of the questionnaire. Most of the answers provided by these students were already included in the list obtained from the previous analysis and few others were added.

In line with previous researches [83-85], the complete list of answers was used to investigate the student behavior. In particular, the a priori analysis, as well as the analysis of real students' answers, made possible to identify three typical answering strategies (see Table I), each one characterized by a different level of efficacy on facing and solving real-context problems. The construction of analytical categories was based on a careful reading of the students' answers by us, by using the framework provided by domain-specific expertise and a phenomenographic approach [86-88].

The practical or everyday (pe-type) answering strategy is characteristic of a student that, despite the diligence of attending the lecture, remains embedded in the everyday commonsense explanation and does not succeed to transit

TABLE I. Typology of answering strategies of students facing real-life problematic situations.

\begin{tabular}{|c|c|c|}
\hline Practical or everyday (pe-type) & Descriptive (de-type) & Explicative (ex-type) \\
\hline $\begin{array}{l}\text { The student faces practical physics } \\
\text { problems by using only their } \\
\text { commonsense experience. The answer } \\
\text { that one provides contains examples from } \\
\text { everyday life and, in some cases, physical } \\
\text { quantities, which are mentioned but not } \\
\text { usefully connected within each other and } \\
\text { do not provide a coherent explanation of } \\
\text { the described phenomenon. }\end{array}$ & $\begin{array}{l}\text { The student approaches the problem } \\
\text { resolution by focusing on their theoretical } \\
\text { background of knowledge, but one is not } \\
\text { able to find the appropriate connection } \\
\text { between the studied theories and the } \\
\text { specific context in which the problem is } \\
\text { constructed. The answer that one provides, } \\
\text { always recalls the statement of a physics } \\
\text { law or contains one or more mathematical } \\
\text { expressions, attempting to give a } \\
\text { reasonable description of the observed } \\
\text { phenomenon, but without any further step } \\
\text { towards the problem resolution. }\end{array}$ & $\begin{array}{l}\text { The student approaches the resolution of } \\
\text { practical problems by drawing from their } \\
\text { theoretical background of knowledge, } \\
\text { applying the studied theories to the } \\
\text { appropriate physical context and achieving } \\
\text { a successful explanation of the proposed } \\
\text { problem. The answer that one provides may } \\
\text { contain a textual explanation or a } \\
\text { mathematical formulation of the problem; in } \\
\text { both cases the problem is well addressed, } \\
\text { the most relevant physical quantity involved } \\
\text { in the process is identified and a reasonable } \\
\text { explicative model is provided. }\end{array}$ \\
\hline
\end{tabular}


up to a scientific comprehension of the observed phenomena. The descriptive strategy (de-type) pertains to college level students who generally spend a lot of time studying physics laws and theories, but often in a purely mnemonic formulation, and forcedly biased towards a list of unrelated concepts. The explicative (ex-type) strategy refers to students who achieved a high level of an effective knowledge, which makes them able to search and find explicative models for the resolution of common life scientific problems.

The final version of the questionnaire and the complete list of answers collected during the validation phase and the research study are reported in Appendixes A and B, respectively. In Appendix B, each answer is coded by using a five-character code: the first two identify the question number, the third and fourth refer to the typology of answering strategies, and the last one codes the specific answer given to the question.

As a final step, we, independently from each other, associated all collected answers to three "profiles" characterized by the answering strategies reported in Table I. Discordances between researchers' classification tables were found in some cases, in particular when a student answer was classified by using different strategies or due to different interpretations of students' statements. This happened 8 times when comparing the tables of researchers 1 and 2, 7 times for researchers 1 and 3, 10 times for researchers 1 and 4, 7 times for researchers 2 and 3, 9 times for researchers 2 and 4 , and 8 times for researchers 3 and 4 . Hence, a good interrater reliability of the analysis was found, with a global percentage of accordance of about 98\% between the analysis tables of the researchers. The discordances were negotiated in order to get to a unique classification of the student answers (Table II). Each profile can be considered the model of an "ideal student" answering to all the questionnaire items always demonstrating a given typology of response. These profiles, whose characterizing answers are listed in Table II by using the same codes reported in Appendix B, have been used for the quantitative analysis of our research data.

\section{B. Overview of the statistical implicative analysis}

In this study, the quantitative analysis of our research sample students' responses to the questionnaire has been carried out by using two functions of statistical implicative analysis: the similarity and the implication indexes. The system to be considered for this analysis is defined by the combination of both the group of students and all the different answers they provided to the questionnaire. Here, we briefly define the similarity and implication indexes, and give some details about the use we make of them in this research. They are better described in Ref. [23], where a full theoretical discussion of their derivation and meaning is given, and in Refs. [84] and [85], where applications of their use in specific research contexts are widely discussed.

Lerman's similarity index $[89,90]$ classifies students according to a method of hierarchical clustering [91,92] and it is primarily used to recognize similarities in student behavior (i.e., similar answering strategies). By considering two generic students, labeled as $i$ and $j$, the similarity index is defined as follows:

$$
s(i, j)= \begin{cases}\frac{n_{i \wedge j} \frac{n_{i} n_{j}}{n}}{\sqrt{\frac{n_{i} n_{j}}{n}}} & \text { for } n_{i} \neq n_{j} ; n_{i}, n_{j} \neq 0 ; n_{i}, n_{j} \neq n \\ 1 & \text { for } n_{i}=n_{j},\end{cases}
$$

where $n_{i}$ and $n_{j}$ are the number of answers provided by the students $i$ and $j$, respectively, $n$ is the total number of different answers, and $n_{i \wedge j}$ is the number of answers that the two students have in common.

If we take into account two generic answering strategies, $a$ and $b$, we can define the implication index, $q(a, \bar{b})$ :

TABLE II. Classification of answers to the questionnaire within the three typologies of Table I.

\begin{tabular}{lccc}
\hline \hline Question & Answers of pe-type & Answers of de-type & Answers of ex-type \\
\hline 1 & Q1peA to Q1peE & Q1deA to Q1deE & Q1exA, Q1exB \\
2 & Q2peA to Q2peE & Q2deA to Q2deG & Q2exA to Q2exC \\
3 & Q3peA to Q3peD & Q3deA to Q3deI & Q3exA to Q3exC \\
4 & Q4peA to Q4peD & Q4deA to Q4deH & Q4exA to Q4exC \\
5 & Q5peA to Q5peE & Q5deA to Q5deE & Q5exA to Q5exC \\
6 & Q6peA to Q6peE & Q6deA to Q6deE & Q6exA to Q6exC \\
7 & Q7peA to Q7peG & Q7deA to Q7deF & Q7exA to Q7exC \\
8 & Q8peA, Q8peB & Q8deA to Q8deC & Q8exA, Q8exB \\
9 & Q9peA, Q9peB & Q9deA to Q9deC & Q9exA, Q9exB \\
10 & Qpe10, Q10peB & Q10deA to Q10deD & Q10exA, Q10exB \\
11 & Q11peA, Q11peB & Q11deA & Q11exA \\
12 & Q12peA, Q12peB & Q12deA & Q12exA \\
13 & Q13peA & Q13deA, Q13deB & Q13exA, Q13exB \\
14 & Q14peA & Q14deA to Q14deC & Q14exA, Q14exB \\
15 & Q15peA & Q15deA, Q15deB & Q15exA \\
\hline \hline
\end{tabular}




$$
q(a, \bar{b})= \begin{cases}\frac{n_{a \wedge \bar{b}}-\frac{n_{a} n_{\bar{b}}}{\sqrt{n_{a} n_{\bar{b}}}}}{n} & \text { for } n_{a} \neq n \wedge n_{b} \neq n \quad n_{a} \neq 0 ; n_{\bar{b}} \neq 0 \\ 1 & \text { for } n_{a}=n \vee n_{b}=n,\end{cases}
$$

where $n_{a}$ is the number of students that put into action the strategy $a, n_{\bar{b}}$ is the number of students not putting into action the strategy $b$ (i.e., using all possible strategies except $b), n$ is the total number of students (30, in our case), and $n_{a \wedge \bar{b}}$ is the number of students using both the strategy $a$ and not using strategy $b$.

In our study, the similarity index $s(i, j)$ is mainly used to detect groupings of student behaviors. In particular, we use it to identify possible clusters of answering strategies with respect to the similarity of students' approaches to solve common life problems in thermal physics (see Tables I and II). The use of ideal profiles of individuals participating in a survey or research is common in many research papers $[23,84,85,93]$ and the results reported in the literature on this subject validate this method both theoretically and experimentally. The implication index $q(a, \bar{b})$ allows us to find relationships (or implications) between different answering strategies activated in each questionnaire and to study their coherence in the proposed framework of the multiple approaches adopted to face thermal experiences. The implication index $q(a, \bar{b})$ is able to provide the finegrain details about implications between the strategies and it is also used to better specify the similarity results.

\section{RESULTS}

In this section we report and analyze the results obtained by administrating the questionnaire to our research sample of engineering undergraduates both prior to and after the accomplishment of the OI-based learning experience. All their answers were independently analyzed by us and classified by using the list of responses collected by the researchers during the validation process. A first remarkable finding was the presence of all the answers into the list of responses reported in Appendix B, confirming the robustness of our questionnaire in terms of internal validity and reliability.

This section is divided into two main subsections. The first one describes the outcomes from our study within the epistemological perspective of different problem-solving approaches, obtained by performing a similarity-based statistical analysis. The second subsection provides an in-depth analysis of students' responses, by focusing on implications between different students' answering strategies, with the aim to analyze the connection between students' epistemological profiles and those thermal physics concepts that the students learned, but do not succeed on using them effectively to solve a problem.

\section{A. Epistemological framework of students' problem-solving strategies}

We have analyzed the students' outcomes by means of the CHIC software [94,95], which has been used to quantify the similarity relationship between two or more students. The analysis of CHIC similarity between real students' answering strategies and those associated to the three ideal students' profiles has been performed separately for each student of the sample. For analysis purpose, we have included in CHIC input three "ideal students" characterized by a complete coherence in answering the questionnaire by adopting exclusively one of the three strategies mentioned above. A pe-type ideal student always answers the questionnaire items by adopting the practical or everyday strategy reported in the second column of Table II. Similarly, descriptive and explicative ideal students always answer by using the strategies reported in the third and fourth columns of Table II. For each answer to a question, CHIC associates a real student with one of the three "ideal profiles" if the student used at least one of the profilerelated answering strategies reported in Table I for that question, as an example, if a student used the strategy Q5exA, Q5exB, or Q5exC, they are classified as 100\% similar (in question 5) to the explicative profile.

In order to investigate the presence of patterns of similarities in students' problem-solving strategies we have compared pre- and postinstruction data within the two similarity graphs shown in Fig. 2. Here, the three squares are the vertexes of an equilateral triangle with side length equal to unity and represent the three epistemological typologies of problem approaching. The distance $d$ from each one of these vertexes is related to the similarity index $s$ by the relation $d=1-s$. The $x$ and $y$ represent the coordinates in a similarity space where the proximity to a specific vertex implies a high value of similarity with that typology, and vice versa. The concentric circumferences mark the distances $0.25,0.5,0.75$, and 1 from the vertexes and the dots represent the students. Different colors are used to mark students' membership to a specific group.

Preinstruction data [Fig. 2(a)] confirm the presence of a main cluster of similarity, with respect to the de-type ideal profile and of a less populated one, related to similarity with the ex-type profile. Only student 5 shows a similarity index that allow us to classify him as mainly similar to the pe-type profile, while students 10,26 , and 13 are exactly in the middle between the practical or everyday and descriptive typologies. This dual clustering is significantly modified in postinstruction data [Fig. 2(b)], where the strong reduction of pe-type similarity (greater distances from practical or everyday vertex) and the significant increase in the number of explicative strategies both contributed to form a dominant ex- or de-type cluster of similarity. In both panels of Fig. 2 the paucity of dots with respect to the expected number (30 students) is only apparent, because several students share the same similarity indexes. This can be observed in Fig. 3, where the similarity index for all the real students, with respect to the three typologies, are shown. Left and right panels show the preinstruction and postinstruction data, respectively. Each line in the plot is 

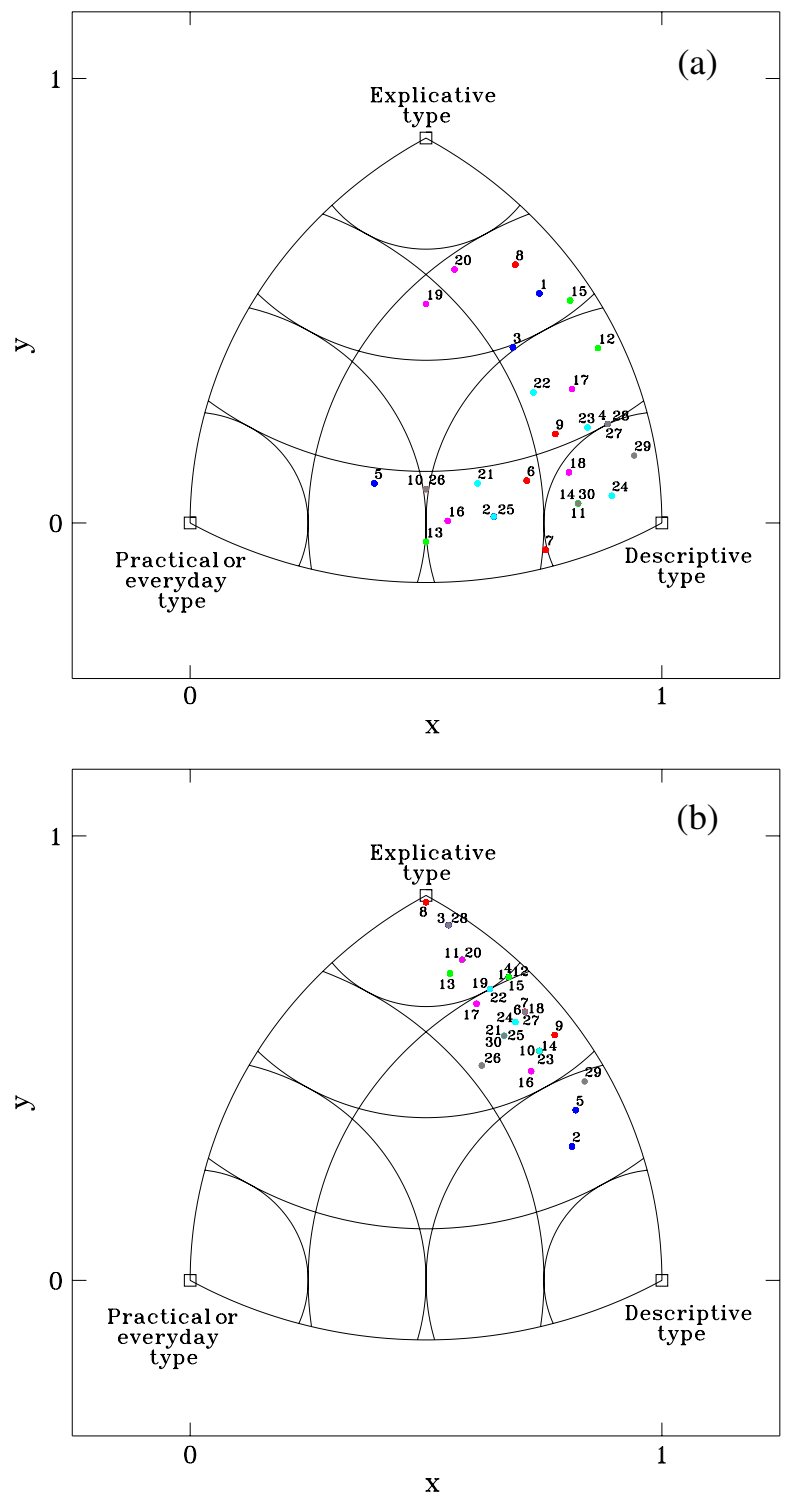

FIG. 2 (color online). Similarity graph for preinstruction (a) and postinstruction data (b). The squares indicate the vertexes of an equilateral triangle with side length equal to unity and represent the practical or everyday, descriptive and explicative typologies. The $x$ and $y$ represent the coordinates in the similarity space. The concentric circumferences mark the distances $0.25,0.5,0.75$, and 1 from the vertexes, the dots and numbers represent the students. Colors are used to identify students who worked within the same group.

referred to a specified student, indexed from 1 to 30 on the abscissa, and connects their values of similarity index computed with respect to the three ideal student profiles (triangles for pe-type, asterisks for de-type, and squares for ex-type). By inspecting the values of similarity index, the following subsamples of students show very close similarity indexes: in preinstruction data this happens for students' numbers (11-14-30, 27-28-4, 10-26, 2-25), in postinstruction for students' numbers (1-4-12-15,
3-28, 19-22, 6-7-18-27, 21-25-30, 10-14-23, 11-20), respectively. As in Fig. 2, the colors here cluster students belonging to the same group.

Preinstruction data show about ten students approaching the questionnaire by adopting a global solving strategy having a similarity greater than $70 \%$ with the de-type. The prevalence of this latter approach is confirmed by an average value of de-type similarity index that settles around 0.6 . However, the presence of a less populated subsample of 5 students [labeled 1, 8, 15, 19 and 20 in the abscissa of Fig. 3(a)] having ex-type similarity indexes between 0.5 and 0.65 is also observed. Surprisingly, for engineering undergraduates already instructed in thermal physics, moderately high values of similarity index associated to the practical or everyday profile are still present in some students. On the other hand, postinstruction data show a better defined situation. In particular, a clear increase of similarity index is observed for the explicative characteristic profile, with the students numbered 3,8 , and 28 reaching similarities greater than $90 \%$ and about a $60 \%$ average ex-type similarity is globally achieved. A central band of de-type similarity index is observed around 0.35 . Significantly lower values of pe-type similarity index are finally recorded.

In Fig. 3 the students' similarities to the three typologies are plotted by following a specific order that allows an easy recognition of the students' membership to their own working group: students labeled $1-5$ belong to the first group, 6-10 to the second, 11-15 to the third, and so on. Colors (on line) are also used to facilitate the identification of a specified group of students. A per-group specific analysis of preinstruction data shows that the average similarity indexes, separately computed per working group and typology, do not deviate from the global average values of similarity for pe-type, de-type, and ex-type by quantities greater than $1.5 \sigma$ (standard deviation), confirming the validity of our selection procedure in terms of uniformity of profiles.

The analysis of students' outcomes by mean of both Figs. 2 and 3, this time performed within the context of their own working-group results, shows a general uniformity of similarity levels, with only few exceptions of students having a similarity index exceeding $1.5 \sigma$ from the average level of the specific typology, with respect to the other members of their own working group. In preinstruction data, this happens for students 13,16 , and 26 with high petype similarities, students 24 and 26 with high de-type similarities and only for the student 8 with high ex-type similarity. Postinstruction data show all groups performing at almost the same level, with the following noteworthy exceptions: student 14 with high de-type similarity, students 8, 22, and 28 with high ex-type similarities, and students 14 and 16 with low ex-type similarities. The students labeled 8, 22, and 28 achieved levels of similarity, with respect to the ex-type, significantly higher than those 

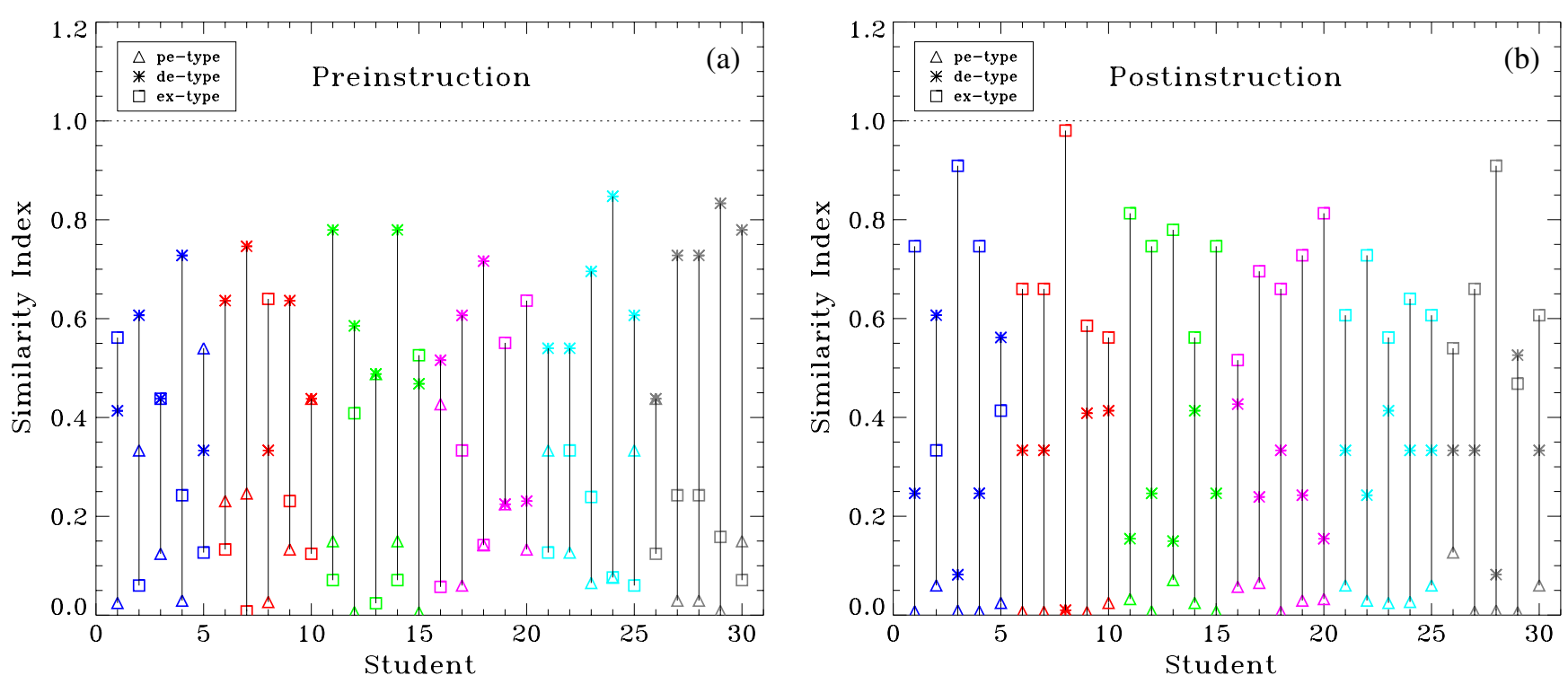

FIG. 3 (color online). Similarity index for each student answering the questionnaire before (left panel) and after (right panel) the carrying out of the OI-based instruction, in relation to the pe-type, de-type, and ex-type characteristic profiles. An integer index on the abscissa is associated to each student and used to identify the learner. As in Fig. 2, colors are used to identify students who worked within the same group.

of their working-group colleagues. However, while we recorded an initial similarity index greater than 0.6 for student 8 , suggesting the presence of higher skills even before this experience, this is not certainly the case of students 22 and 28, who initially are merely on the average. On the other hand, the lower postinstruction outcomes recorded in students 14 and 16 could be related to their high preinstruction values of pe-type similarity. By synthesizing, almost all students performed at about the average levels of pe-type, de-type, and ex-type similarity index that characterize their own working group, except for three students outperforming and two students low performing with respect to the achievements of their colleagues.



FIG. 4. Percentage of students' answers adopting strategies characteristic of pe-type, de-type, or ex-type profile to answer the questionnaire, administered before (black bars) and after (white bars) participating in the OI-based learning experiences.
An overall analysis of the answering strategies adopted by the students to face and solve problems proposed by the questionnaire is shown in Fig. 4. In particular, a summative comparison between pre- and postinstruction data is provided by plotting the percentage of global students' answers as following the classification listed in Table II within the pe-type, de-type, and ex-type profiles.

Preinstruction data show that more than 50\% of students' answers are characterized by a de-type strategy, while about $20 \%$ and $25 \%$ of students' responses can be classified within the typical approaches of the first and third typology, respectively. On the other hand, the percentages of students' answers collected at the conclusion of the OI experience show the prevalence of the ex-type approach. In fact, an overall enhancing of the occurrence frequency of ex-type answering strategy is observed from preinstruction to postinstruction data, with a total percentage of students adopting an effective ex-type approach increasing from about $25 \%$ up to $63 \%$.

\section{B. Implications between different students' answering strategies}

In this subsection we analyze the connections between the students' epistemological difficulties on problem solving and those physics concepts the students studied in their academic courses, but whose knowledge was not meaningful enough to achieve a successful explanation of the proposed problems. In order to do this, we first list the main features of the questions and briefly comment the students' responses, mentioned by using the labeling system provided in Appendix B. 
Question 1.-The aim of the first question is to investigate the ability of the student to find the key parameter in the process of solar irradiation of two identical plates. Many students' answers involved the total surface exposed to solar radiation, neglecting to mention the incident angle. Furthermore, two answers showed evidence of a possible misconception connected to the concept of heat, which was considered as a definite quantity contained in a body (Q1peB, Q1deE).

Question 2.-The key parameter is the absorption of visible radiation. The aim of this question is to investigate the problems related to the concept of black body, which was often considered only the best absorber, forgetting that it is also the best emitter of thermal radiation (Q2deD and Q3deA).

Question 3.-This question deals with the understanding of the process of emission of thermal radiation. Answers Q3deB, Q3deE, Q3deF were strictly connected to the concept of thermal conduction and to the insulation effect obtained by painting the aluminum cylinder. Answer Q3deG showed the presence of a problem related to the identification of the basic mechanism of the cooling process (convection instead of radiation).

Question 4.-This question is focused on the concept of specific heat, but many students did not identify this as the right physical quantity involved in the process. Answers Q4deC, Q4deE, and Q4deG addressed the understanding of the process in terms of thermal conduction. Answers Q4peA and Q4deH deal with the transfer of energy by radiation and on the transmission coefficient. Answer Q4deA took into account insulation effects. Students who answered Q4deB guessed the specific heat as the right physical quantity to be involved in the process, but heat was still considered a quantity to be stored.

Question 5.- In connection with the previous question, here the students were asked to explain the physics governing the cooling process of the two bottles, initially warmed at the same temperature. Answer Q5peA involved the transmission of the visible radiation through the water. Convection was taken into account by answer Q5deA, as already found in answer Q3deG. Answers Q5deB and $\mathrm{Q} 5 \mathrm{deC}$ addressed the understanding of the process in terms of thermal conduction. Answer Q5deD reported again heat as a storable quantity, as did answer Q4deB. Students answering Q5deE supposed the cooling process governed by thermal radiation, by taking into account the sand emissivity.

Question 6.-This question is concerned with the melting of two identical ice cubes placed on top of two plates made of the same material and surface, differing only in their thickness. Students would have to predict whichever of the two ice cubes melts first. Answer Q6peA relates the heat absorbed by the ice cube with the dimension of the plate (bigger plate means bigger heat available). Answer Q6peB is connected to insulation and answers Q6deA,
Q6deB, Q6deC, and Q6deD consider thermal conduction through the plates as the key physical process to take into account in order to explain the melting phenomenon described in the test. The zero law of thermodynamics (answer Q6deE) is reported by those students who are convinced that the two ice cubes melt at the same time.

Question 7.-Similarly to question 6, here students were asked to investigate how much heat is subtracted from a plate by letting melt an ice cube on top of it. Again, two plates having different thickness are considered. The concept "bigger plate means greater resistance to changes" is at the base of the answer Q7peA. Answer Q7peB is connected to insulation and answers Q7deB, Q7deC, and Q7deD consider thermal conduction through the plates. Students answering Q7deE considered the volume of the plate, instead of its mass, as the most relevant quantity.

Question 8.-This question asks the students to choose which of two objects (the first made of glass and the other of plastic) are colder, after a whole night inside a freezer. The aim of inserting this question, despite its simplicity, is to investigate the resistant misconception "temperature vs perception of hot and cold" which is typically observed in students at lower grades of education and should be almost completely absent in college level students. Despite this, we still find students' answers Q8peA and Q8peB asserting that the glass cup is colder than the plastic one. Insulation is taken into account in answer Q8deA.

Question 9.-This question is concerned with the process of thermal conduction and the direction of heat flow. Answers Q9deA and Q9deB focused on the right physical quantity, but without being sufficiently exhaustive. A resistant misconception between temperature and heat is evident in answer Q9deC.

Question 10.-Heat capacity is the main topic of this question. In answers Q10peA and Q10peB students considered the volume of an object as the same physical quantity of its mass. The concept of thermal reservoir is considered in answer Q10deB, but the students did not capture the similarity between the hot rock dropped into a pail of water and that in the ocean.

Question 11.-The aim of this question is to investigate the student perception of heat exchange by forced convection. The idea of a greater energy exchange is considered by answer Q11deA, but without explicitly citing the physical mechanism involved, as in answer Q11exA.

Question 12.-This question deals with the topic of energy exchange by thermal radiation, by considering the cooling process of a warm object in a vacuum bell jar. Students answering Q12peB and Q12deA, however, considered thermal conduction as the main cooling mechanism.

Question 13.- The aim of this question is to investigate how students describe the well-known phenomenon of hot air at lower density moving upwards because of natural convection. Answer Q13deA points out the presence of a 


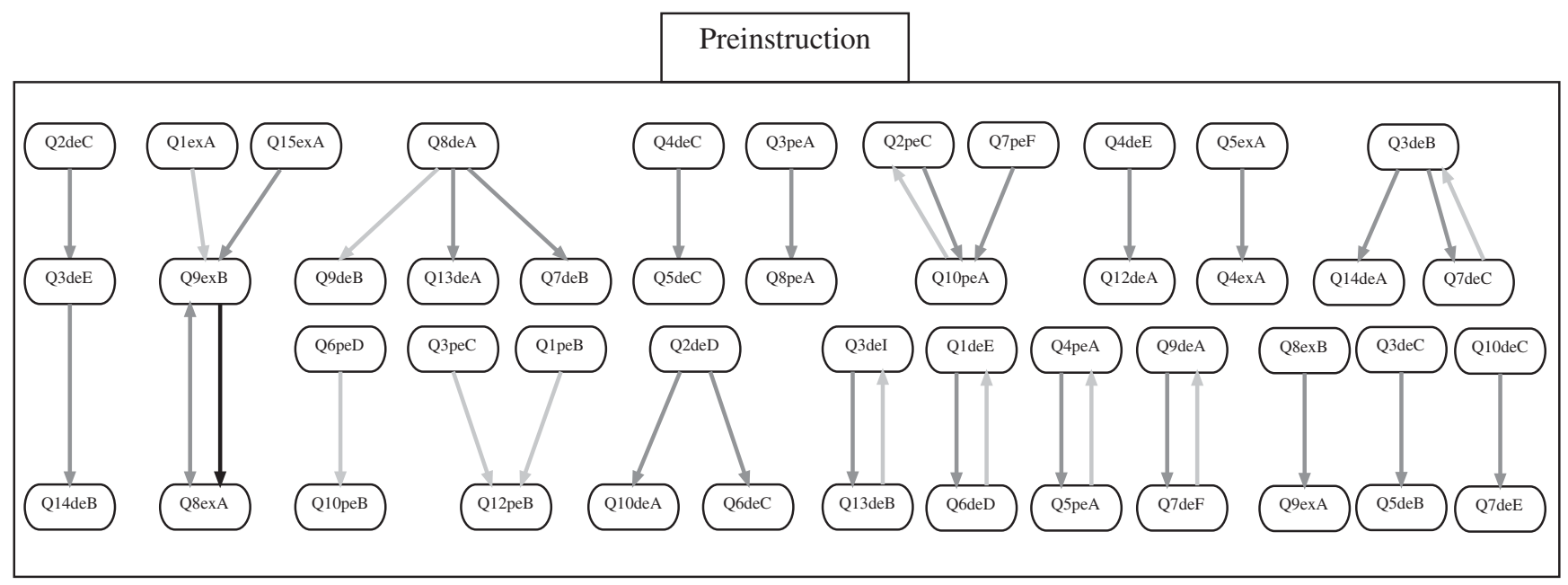

FIG. 5. Implicative graph for the answers to the questionnaire in preinstruction administration. Black arrows indicate an incidence of implication greater than $93 \%$ between two connected answers. The gray color is used to indicate implications between $90 \%$ and $93 \%$; light gray arrows indicate an implication between $87 \%$ and $90 \%$. In the upper panel, rectangles represent student answers to the questionnaire as reported and labeled in Appendix B.

possible misconception concerning the motion of heat instead of the air.

Question 14.-The situation described in this question put the students in front of a typical real-world problem of insulation in the context of a house. The main heat transfer mechanisms involved here are radiation and natural convection. Students answering Q14deA considered the exposition of the higher floor to solar radiation, but they did not write anything about the ground floor. Answer Q14deB takes into account the problem of insulation, but heat was considered again a quantity captured inside a place.

Question 15.-This question explicitly treats the practical situation of higher temperatures in rooms at upper floors. As in question 14, the main heat transfer mechanisms involved are radiation and natural convection, but students often "forget" to mention one of the two, as in answer Q15deA (only radiation) or Q15deB (only convection).

In order to deepen the analysis of the students' responses and link the three problem-solving epistemological profiles discussed above with the physics concepts addressed in the questionnaire, we used the CHIC software to identify implicative associations between students' answering strategies. Figure 5 shows the implicative graph between some of the answering strategies used by the students before experiencing the OI path. Student's answers are connected each other by means of arrows. For simplicity, in Fig. 5 we chose to represent only the answering strategies that imply another one with a significance level of at least $93 \%$ (black arrows), 90\% (gray arrows), and 87\% (light gray arrows). Moreover, in the following we will discuss only implications that involve at least 5 students. We point out that in CHIC graphs implications have to be read only between pairs of strategies.
Preinstruction data show interesting implications from the cognitive point of view. Many significant implications shown in Fig. 5 involve practical or everyday and descriptive strategies. Students showing problematic answers by mentioning thermal insulation effects in answer Q3deE, do the same in answer Q14deB. A similar implication is found between the answer Q8deA and the answers Q9deB and Q7deB, which regards the inappropriate application of the theory of thermal conduction. This latter problem is also a common feature of the implications between the following couples of answers: Q4deC and Q5deC, Q4deE and Q12deA, Q3deB and Q7deC. Students citing the definition of heat as energy in transit (Q9deA), without responding to the practical question, have similar difficulties in applying the zero law of thermodynamics $(\mathrm{Q} 7 \mathrm{deF})$. An expected implication, typical of the theory-focused student profile (de-type), is observed in students' answers mentioning the Fourier law when answering question 1 with Q1deE and 6 with Q6deD. Implications concerning the lack of a fruitful application of the theories of heat transfer by radiation and conduction are observed between the following answers: Q2deD-Q6deC, Q4peA-Q5peA, Q3deB-Q14deA, Q3deCQ5deB, and Q3deI-Q13deB. Students answering by following a marked practical or everyday profile bring about implications between answers Q3peC and Q1peB with Q12peB, Q3peA-Q8peA, Q2peC, and Q7peF with Q10peA.

Some significant implications shown in Fig. 5, however, regard explicative strategies. In particular, a 93\% implication is found between answers Q9exB and Q8exA, which are both classified as explicative type and represent the connection between a meaningful understanding of the concept of heat flow and that of thermal equilibrium. Another implication involving the ex-type strategy is 


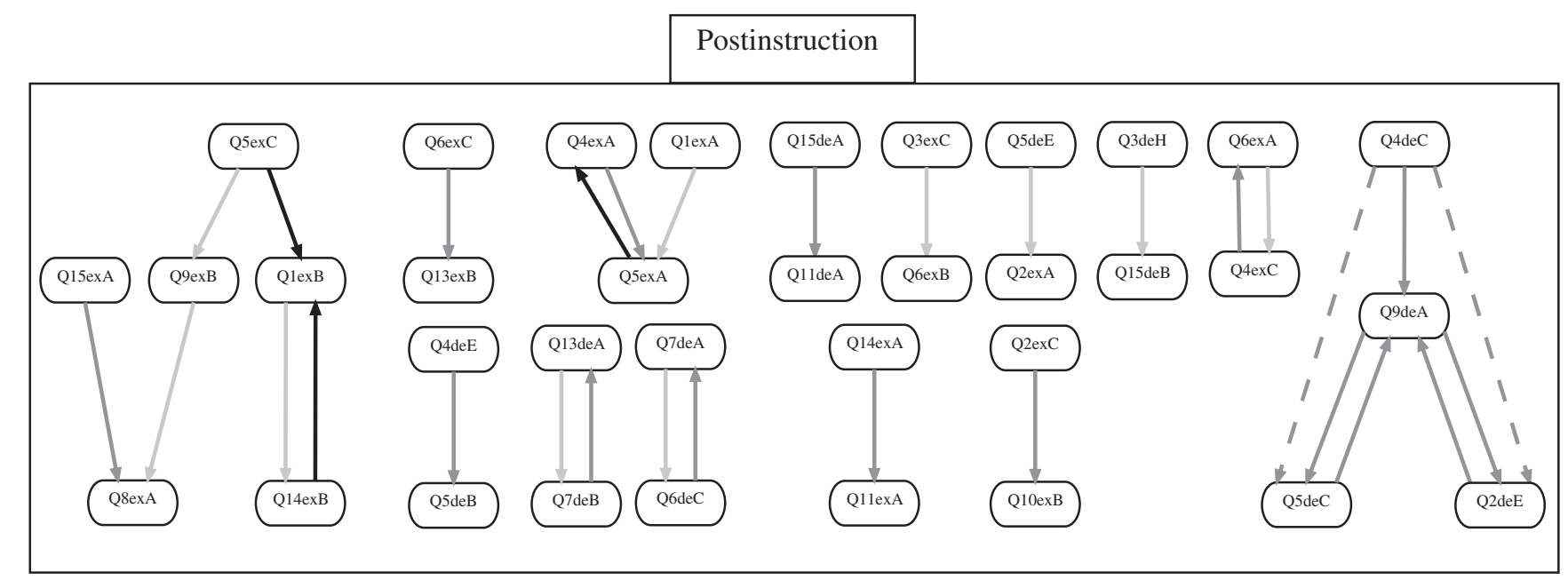

FIG. 6. Implicative graph for the answers to the questionnaire in postinstruction administration. As in Fig. 4, black arrows indicate an incidence of implication greater than the $93 \%$ between two connected strategies. The gray color is used to indicate implications between 90\% and 93\%; light gray arrows indicate an implication between $87 \%$ and $90 \%$. Dashed lines show transitive implications.

observed between answers Q8exB and Q9exA, with a percentage of $90 \%$, where students understanding the zero law of thermodynamics and the concept of thermal equilibrium have also a good comprehension of the physics expressed by the II principle of thermodynamics. The last ex-type implication regards the answers Q5exA and Q4exA, which are both related to the corrected application of the specific heat concept.

Postinstruction data, shown in Fig. 6, highlight a significant improvement in terms of the number of implications involving students' answers classified within the explicative ideal profile. These answers are clear indicators of development of problem-solving skills that use scientific concepts in an appropriate way.

In fact, students having achieved the ability to face a practical situation, by identifying the right physical quantity to be managed to solve the problem, will be able to do the same in many different specific contexts. This is the case, for example, of the $93 \%$ implications found between answers Q5exC-Q1exB, Q14exB-Q1exB, 90\% between answers Q6exC-Q13exB, Q2exC-Q10exB, Q14exA-Q11exA, $\mathrm{Q} 15$ exA-Q8exA, and $87 \%$ between answers Q5exCQ9exB, Q9exB-Q8exA, Q1exA-Q5exA, and Q3exCQ6exB. Within the explicative-type strategy, implications having the same physics concept effectively understood are those regarding students' answers Q5exA and Q4exA (specific heat) at 93\%, Q4exC and Q6exA (heat capacity) at 90\%, Q9exB and Q8exA (heat flow and thermal equilibrium), Q6exA and Q4exC (heat capacity) at 87\%.

However, implications involving students' answers within the descriptive strategy are still present, even in postinstruction data, concerning, in particular, with the topic of thermal conduction (Q4deE-Q5deB and Q4deCQ9deA), the concept of thermal power (Q6deC-Q7deA) and the mechanism of energy transfer (Q3deH-Q15deB and
Q15deA-Q11deA). These implications can barely be taken into account (as they involve just five students). However, they still give evidence of an incidence reduction of the related difficulties after the OI learning experience. Moreover, in postinstruction data, no implications with significance level greater than $87 \%$ between answers of practical or everyday type are found.

In synthesis, preinstruction results have shown a direct connection between the pe- or de-type epistemological profiles and some physics concepts that the students have certainly studied in their curricular instruction, but without reaching the meaningful knowledge that is necessary to successfully face and solve common life problems on thermal science. These students demonstrated the ability to hold a merely notional knowledge of the concepts of thermal conduction, heat capacity, the zero law of thermodynamics, heat as energy in transit, and heat transfer by thermal radiation, with difficulties proficiently applying them in finding a solution to problematic situations never encountered before. This finding means that undergraduates traditionally instructed may still experience residual conceptual difficulties that affect their performances on problem solving, as also highlighted by other researchers [79]. A postinstruction increase in the number of ex-type implications has clearly shown that students who provided scientifically exhaustive explanations, demonstrating the achievement of high-order problem-solving skills, were able to address a problem by meaningfully applying several physics concepts in an appropriate way. This evidence suggests that an OI-based learning environment could help science or engineering undergraduates to overcome also their residual conceptual difficulties, in addition to positively addressing the epistemological issue. However, a more detailed research on this question deserves further investigation and could be the subject of a future paper. 


\section{SUMMARY AND CONCLUSIONS}

An OI-based learning environment has been experienced by a sample of mechanical engineering students having already received the traditional physics instruction in their university curriculum. The students were selected to be engaged in a pilot project, specifically designed to investigate the efficacy of an OI-based approach to support the development of high levels problem-solving skills related to both design and inquiry procedures, as well as promoting a more meaningful conceptual understanding of the physics underlying the world of thermal phenomena. Students spent a total of about forty hours planning and realizing a complete scientific research, concerning the experimentation of ideas, the design and practical realizations of smart devices, in the context of a hypothetical project about the construction of a thermodynamically efficient space base on Mars. A questionnaire, specifically developed to investigate the presence of problem-solving related epistemological difficulties affecting the complete understanding of common life phenomena in thermal science, has been administered to students both prior to and after the OI experience. Students' outcomes to the questionnaire have been deeply analyzed in order to answer the research question addressed in this paper.

The statistical analysis of the similarity relationships between students and the three ideal student profiles allowed us to clarify how students modified their epistemological stances with respect to facing thermal phenomena and solving related problems, as a result of the attended OI-based learning experiences. Data reported in Figs. 2 and 3 show that the distribution of the student similarity indexes with respect to the three ideal profiles has been significantly affected by OI-type instruction. In fact, preinstruction results show the presence of a main cluster of similarity, with respect to the de-type ideal profile and of a less populated one, mainly related to similarity with the ex-type profile. Figure 2(b) clearly shows the presence of a postinstruction single ex-type cluster of similarity, with components often pointing out also the use of descriptive-type strategies.

A general significant reduction in the number of postinstruction answers related to the pe-type approach has been found. This essentially means that fewer students now consider their personal commonsense interpretations as valid explanations of the observed phenomena. However, the most significant result is in regard to those students originally adopting a prevalent de-type approach, which is basically characterized by attempts to find a mathematical solution to the problem, without considering conceptually meaningful physical explanations. In fact, while at the beginning of the project the students showed the higher levels of similarity with the de-type profile, at the end of activities the majority of them adopted ex-type reasoning strategies.
We have observed that, even if already instructed by attending traditional courses on thermal science, a significant fraction of students still shows difficulties in facing and solving problems by effectively applying the studied physics concepts. In this study we have quantitatively analyzed the implications between different students' answers, with the aim of connecting their epistemological difficulties to specific physics concepts. We have found high percentages of students who provided problematic answers to questions requiring the effective application of the concept of specific heat or still considering heat as a storable quantity, instead of the energy exchanged because of a temperature difference, showing significant difficulties in identifying the relevant physical quantity involved in a dynamic process characterized by two or more variables, confirming the results reported in Refs. [6,79]. Other difficulties were experienced by our undergraduates when answering questions about heat transfer by multiple transport mechanisms. On writing their solution, students usually take into account only one transport mechanism, probably the one they believe to be dominant, and do not even consider the possibility of a combined action with the others. The problem of "forgetting to mention" a mechanism was observed in our student sample for convection or thermal radiation, but not in the case of thermal conduction. The latter is the most known mechanism to the students, though the other two are equally experienced in their everyday lives, but probably without being completely aware. Thermal conduction needs the presence of a medium to transport the energy and people seeing the medium can easily imagine something (thermal energy) that travels across it. Convection needs a medium too, but learners have more difficulties figuring out the motion of the particles when the fluid is not visible, such as the air. In this view, thermal radiation, being able to travel even in the vacuum, is the transport mechanism that students most easily forget to take into account, even if they are, of course, aware of the heating mechanism by solar radiation. The last difficulty we have noticed in our students is specifically in regard to their approach to answering the preinstruction questionnaire: when facing a problem, some students immediately started by opening the "handbook of the engineer," trying to catch the right formula to be used to answer the questions. This behavior could be ascribed to their past learning experiences, which were probably too concentrated on memorizing formulas and solving standard problems by applying defined procedures, instead of deepening their view of science as a global challenging research for coherent explanations.

The way students answered the questionnaire before and after instruction also gave us insight into a change in their way of approaching the proposed situations. In fact, before instruction they considered the questionnaire as a sort of evaluation test, searching for possible formulas in their engineering manuals and answering the questions with 
short, mathematically oriented solutions. After the OI experience, they approached the questionnaire in a more competent way, by trying to explain their answers, inquiring about the described phenomenon and reasoning on the dominant energy transport mechanism and the most relevant physical quantities involved in the processes. This finding is confirmed by the observed reduction in the number of postinstruction implications involving pe-type and de-type responses and by the increase in the number of implications regarding the ex-type typology. The global improvement in the students' problem-solving strategies, quantitatively established by the percentage increase of implications between postinstruction ex-type answers to different questions, is a clear indicator of the efficacy of OIbased learning activities to activate more efficient problemsolving skills. However, since our study does not compare open and guided inquiry-based teaching approaches, we cannot exclude that a guided inquiry-based learning environment would produce positive outcomes as well. Nevertheless, our results provide evidence that OI experiences contribute positively to increasing student abilities in problem solving, by providing the activation of appropriate epistemological resources.

Finally, although some studies $[44,45]$ showed that OIbased teaching or learning approaches, requiring the greatest cognitive demand from students in terms of scientific reasoning, may induce feelings of inadequacy or frustration, preliminary analysis of our video-recorded data do not show any evidence of this. The choice made by the educators to drive the students' inquiry within the context of a space science challenge strongly motivated the students. They were, of course, conscious that their research work was not part of a real space project, but they participated in the activities with equally high emotional involvement, being convinced of the importance of actively participating in a real research experience. After the conclusion of this experience many students spontaneously emailed the educators their positive feedback, highlighting the benefits of this OI learning environment in terms of developing practical and reasoning skills about learned concepts. Moreover, even if not required, each student group prepared an oral contribution describing the OI experience and enthusiastically presented the results of their experimental activities in front of the faculty council for mechanical engineering. In conclusion, it appears that our students very much appreciated this "new" teaching approach, confirming that a highly motivating OI-based learning environment may minimize the appearance of negative psychological effects.

\section{FINAL REMARKS AND FUTURE OPPORTUNITIES}

An effective teaching of physics in engineering should provide the students with an adequate background of discipline specific information and strengthen their creative thinking and design skills, with the general aim of promoting a vision of natural phenomena in terms of concepts and developing abilities of designing and putting in action expertlike problem-solving strategies.

Traditional methods of teaching thermal science at the university level, mainly based on the transmission of information and laws, bring about learning that is not lasting or effective. The encouraging results presented in this paper have been obtained by engaging and motivating a small sample of engineering undergraduates to perform independent OI-based research activities, which, however, were carried out over a short time interval. The application of OI-based strategies within learning experiences more extended in time could bring about even better outcomes. However, even considering all the limitations of a case study, our findings provide positive indications towards the inclusion of design-based researchlike activities, within an OI-based learning environment, in the standard curricula of engineering education, as a valid integration to traditional teaching. In this way, it could be possible to achieve a more useful and effective meaningful knowledge of difficult physics concepts, promoting the strengthening of the reasoning skills of future engineers and their vision of the nature of science.

Forthcoming results from video analysis and the students' interviews collected during this project will contribute to a better understanding of the dynamics involving the acquisition of metacognitive and autonomy skills taking place during an OI-based instruction, and will be useful to improving the design of future learning environments for science and engineering students.

\section{ACKNOWLEDGMENTS}

The authors wish to thank Dr. B. Di Paola for his useful comments and suggestions on the research activity, and Professor A. Pasta and Professor L. D'Acquisto of mechanical engineering department, who kindly coordinated the relationships between the authors and the faculty of engineering. One of us (N.P.) also wishes to thank Professor E. Redish for a very short but fruitful discussion on the occasion of the World Conference on Physics Education (Istanbul, August 2012). This work was partially supported by MIUR and FP7 Establish Project (EU G.A. 244749).

\section{APPENDIX A: THE QUESTIONNAIRE}

(1) Two equal bricks are exposed to the sunlight for 15 minutes; one is placed vertically and the other one is placed horizontally with respect to the ground. What do we observe at the end?

(a) The temperature of the vertical brick is greater than that of the horizontal one.

(b) The temperature of the vertical brick is lower than that of the horizontal one. 
(c) The two bricks are heated up the same temperature.

(d) I don't know.

Explain your answer:

(2) Two equal metal plates, the first one painted white and the second one painted black, are exposed to the sunlight in the same way and for the same time interval.

Which of the two plates reaches the highest temperature?

(a) White.

(b) Black.

(c) They reach the same temperature.

(d) I don't know.

Explain your answer:

(3) Two equal aluminum cylinders, the first one painted white and the second unpainted, are heated up to reach the same temperature and then left to cool. What do we observe?

(a) The white-painted cylinder cools first.

(b) The unpainted cylinder cools first.

(c) The two cylinders cool by maintaining the same temperatures.

(d) I don't know.

Explain your answer:

(4) Two equal plastic bottles, the first one filled with water and the second with sand, having almost the same weight, are exposed to the sunlight in the same way and for the same time interval (15 minutes); which of the two bottles reaches the highest temperature?
(a) The one filled with water.
(b) The one filled with sand.
(c) They reach the same temperature.
(d) I don't know.
Explain your answer:

(5) After having heated the two bottles of question (4) up to the same temperature, we bring them out from the direct exposure of sunlight and observe their cooling. Which of the two bottles cools faster?
(a) The one filled with water.
(b) The one filled with sand.
(c) They cool maintaining the same temperature.
(d) I don't know.
Explain your answer:

(6) Two ice cubes are extracted from the freezer and placed on top of two aluminum plates at room temperature, having the same surface but different thickness. It is observed that:

(a) The ice melts more quickly if placed on top of the thicker plate.

(b) The ice melts more quickly if placed on top of the thinner plate.

(c) The ice melts in the same way on top of the two plates. (d) I don't know.

Explain your answer:

(7) Two ice cubes are extracted from the freezer and placed on top of two aluminum plates at room temperature, having the same surface but different thickness. At the end of the melting phase we measure the average surface temperature of the two plates and we find that:

(a) The temperature of the thicker plate is lower than the that of thinner one.

(b) The temperature of the thicker plate is higher than the that of thinner one.

(c) The temperature of the two plates is the same.

(d) I don't know.

Explain your answer:

(8) A glass beaker and a plastic cup are left empty inside a freezer for a whole night. The following day, the two objects are extracted from the freezer and the temperature of the glass beaker is immediately measured. It is:

(a) Higher than that of the plastic cup.

(b) Equal to that of the plastic cup.

(c) Lower than that of the plastic cup. Explain your answer:

(9) If you hold one end of a metal nail against a piece of ice, the end in your hand soon becomes cold. Does cold flow from the ice to your hand?

Explain:

(10) If you drop a hot rock into a pail of water, the temperature of the rock and the water will change until both are equal. The rock will cool and the water will warm. Is this true if the rock is dropped into the Atlantic Ocean? Explain:

(11) A cool object placed in front of a fan:

(a) Heats up more slowly.

(b) Heats up more quickly.

(c) Heats up the same.

Explain:

(12) A warm object is arranged inside a glass jar bell from which the air is expelled by a vacuum pump. It:

(a) Cools anyway.

(b) Does not cool.

(c) I don't know.

Explain your answer:

(13) In a house, two empty rooms having equal surface and identical exposure to the sunlight, have only one window, which is always left open during the day in the summer season. The only difference between the two rooms is the position height of the window: one is placed in the middle of the wall and the other is placed higher. Which of the two rooms is fresher? Explain your answer:

(14) In a three-story house there are three apartments, one for each floor, not equipped with heaters. The 
apartment at first floor is the warmest.

Try to guess the cause:

(15) During a hot summer day the rooms upstairs are warmer than those downstairs. Why?

\section{APPENDIX B: STUDENTS' ANSWERS TO THE QUESTIONNAIRE}

Q1peA: "Answer (a) because of the greater surface of interaction with the surrounding environment."

Q1peB: "Answer (b) because of the greater surface exposed to the source of heat."

Q1peC: "Answer (b) because of the greater surface exposed to the Sun, therefore higher temperature."

Q1peD: "Answer (c) because it is likely that, after 15 minutes, the two bricks have reached the same temperature."

Q1peE: "Answer (d) because I have never experienced this phenomenon before."

Q1deA: "Answer (a) because of the greater surface of thermal exchange."

Q1deB: "Answer (b) because of the greater surface exposed to solar radiation, therefore it absorbs more energy."

Q1deC: "Answer (b) because the horizontal brick completely absorbs the solar power that hits on it."

Q1deD: "Answer (b) because of the Stefan law."

Q1deE: "Answer (b) because of the low temperature gradient (Fourier law) along the depth of the brick, therefore the horizontal brick will hold the heat for a longer time."

Q1exA: "Answer (b) because of the greater surface with greater orthogonal component to the incident solar radiation."

Q1exB: "Answer (b) because the increase of temperature is caused by the quantity of absorbed energy, which is greater when the surface is placed orthogonally with respect to the incident radiation."

Q2peA: "Answer (a) because the white color contains all colors, including the black one and many more."

Q2peB: "Answer (b) because in the summer season objects painted by dark colors are hotter."

Q2peC: "Answer (b) because usually black objects absorb more heat."

Q2peD: "Answer (c) because, in my experience, colors do not affect the temperature of an object."

Q2peE: "Answer (d) because I have never experienced this phenomenon before."

Q2deA: "Answer (a) because the color temperature corresponding to the white is the highest one."

Q2deB: "Answer (b) because the black color is a combination of all bright bands and entirely absorbs radiations."

Q2deC: "Answer (b) because the refraction index is lower in the black plate with respect to the white one."
Q2deD: "Answer (b) because the black body is the perfect body absorbing light."

Q2deE: "Answer (b) because the black body is the perfect body absorbing thermal energy, therefore the black plate is heated more than the white one."

Q2deF: "Answer (b) because the black plate has a lower emissivity with respect to the white one."

Q2deG: "Answer (b) because the black body is the best emitter, $\varepsilon=1$."

Q2exA: "Answer (b) because the black color increases the absorption factor."

Q2exB: "Answer (b) because the black color means that all visible radiation is not reflected but absorbed."

Q2exC: "Answer (d) because it depends on the absorption coefficient of the paints."

Q3peA: "Answer (a) because the white color is the brightest and let more energy to come out of the white cylinder."

Q3peB: "Answer (b) because in this case the energy is more free to leave the cylinder."

Q3peC: "Answer (c) because they are made by the same material and, in my experience, colors do not affect the temperature of an object."

Q3peD: "Answer (d) because I have never experienced this phenomenon before."

Q3deA: "Answer (a) because the perfect white body is the ideal emitter of light."

Q3deB: "Answer (b) because the paint has a lower conductivity with respect to the aluminum (values reported from a handbook)."

Q3deC: "Answer (b) because aluminum has a polished surface and therefore reflects better."

Q3deD: "Answer (b) because the white surface emits a lower quantity of heat by thermal radiation."

Q3deE: "Answer (b) because the white paint could function as a thermal insulator, permitting a slower transfer of heat."

Q3deF: "Answer (b) because the white paint lowers the cylinder conductivity."

Q3deG: "Answer (c) because convection is the prevalent cooling mechanism."

Q3deH: "Answer (c) because, neglecting insulation effects, the color of the paint should not affect the cooling process."

Q3deI: "Answer (d) because it depends on the thermal conduction coefficient."

Q3exA: "Answer (a) because the paint has a greater emissivity."

Q3exB: "Answer (a) because the polished aluminum cylinder is characterized by a low emissivity and the paint increases the emissivity."

Q3exC: "Answer (a) because the two cylinders emit radiation in the infrared and the paint has a greater emissivity in that range of electromagnetic spectrum.” 
Q4peA: "Answer (a) because I can see through the water and this means that solar radiation can penetrate inside the bottle filled with water and warm it more easily."

Q4peB: "Answer (b) because, during a summer day at the seaside, we feel the sand hotter than the sea water ..... it should depend on the specific heat."

Q4peC: "Answer (c) because I can't see any difference between the two bottles."

Q4peD: "Answer (d) because I have never experienced this phenomenon before."

Q4deA: "Answer (a) because the sand is a thermal insulator."

Q4deB: "Answer (a) because the specific heat of the water is greater than that of the sand and the specific heat is the physical quantity which gives information on heat storage."

Q4deC: "Answer (a) because the thermal conduction coefficient of the water is greater than that of the sand."

Q4deD: "Answer (a) because water absorbs energy more quickly."

Q4deE: "Answer (b) because of a lower thermal conductivity."

Q4deF: "Answer (b) because of the higher specific heat of the sand."

Q4deG: "Answer (b) because sand should have a greater thermal conductivity."

Q4deH: "Answer (b) because the sand is opaque to solar radiation and therefore the surface heats up more quickly."

Q4exA: "Answer (b) because the specific heat of the sand is lower than that of the water."

Q4exB: "Answer (b) because the increase of the temperature is inversely proportional to the specific heat and that of the sand is lower than that of the water."

Q4exC: "Answer (b) because we need less energy to heat sand with respect to what we need to warm the same amount of water (calculations by means of specific heat reported)."

Q5peA: "Answer (a) because water is transparent and releases out energy more quickly."

Q5peB: "Answer (b) because at the seaside during the night the sand cools faster than the sea water."

Q5peC: "Answer (b) because the sand is a solid material and cannot storage a big amount of heat."

Q4peD: "Answer (c) because I can't see any difference between the two bottles."

Q4peE: "Answer (d) because I have never experienced this phenomenon before."

Q5deA: "Answer (a) because convection facilitates heat dispersion."

Q5deB: "Answer (a) because a lower thermal conductivity brings to a greater difference in temperature."

Q5deC: "Answer (b) because of the thermal conductivity."

Q5deD: "Answer (b) because the specific heat, which is the physical quantity related to the storage of heat, is greater in the bottle filled with water."
Q5deE: "Answer (b) because sand emissivity is higher than that of the water."

Q5exA: "Answer (b) because the specific heat of the sand is lower than that of the water and, therefore, a lower amount of energy is needed to cool it."

Q5exB: "Answer (b) because, being the specific heat of the sand lower than that of the water and assuming the same quantity of heat subtracted, the sand will reach soon a lower temperature."

Q5exC: "Answer (b) because, by assuming the same amount of energy subtracted, the temperature of the bottle filled with water will be higher than that one filled with sand because of its higher specific heat."

Q6peA: "Answer (a) because heat absorbed by the ice cube is greater from the thicker plate."

Q6peB: "Answer (b) because the thinner plate has a lower insulation effect to the heat transfer from the table."

Q6peC: "Answer (c) because the temperature of the surrounding environment is the same."

Q6peD: "Answer (c) because only the contact surface is important, not the thickness."

Q6peE: "Answer (d) because I have never experienced this phenomenon before."

Q6deA: "Answer (a) because aluminum is a good thermal conductor."

Q6deB: "Answer (b) because the speed of heat transfer by conduction is inversely proportional to the thickness, therefore the thinner plate transfers more heat to the ice cube."

Q6deC: "Answer (b) because the thermal power is inversely proportional to the thickness (formula)."

Q6deD: "Answer (b) because of the Fourier law (equation)."

Q6deE: "Answer (c) because of the zero law of thermodynamics."

Q6exA: "Answer (a) because the thicker plate, having a bigger mass, has much more particles with kinetic energy $1 / 2 \mathrm{mv}^{2}=3 / 2 \mathrm{KT}$, which is available to be transferred as heat to the ice cube."

Q6exB: "Answer (a) because the thicker plate absorbs heat from the ice cube more faster because of its greater thermal capacity."

Q6exC: "Answer (a) because the heat transfer from the plate depends on its thermal capacity, which is greater in the more massive one."

Q7peA: "Answer (a) because a big object is more resistant to changes (in temperature) with respect to a smaller one."

Q7peB: "Answer (b) because the thicker plate has a greater insulation effect to the heat transfer from the table."

Q7peC: "Answer (c) because the temperature of the surrounding environment is the same."

Q7peD: "Answer (c) because only the contact surface is important, not the thickness." 
Q7peE: "Answer (c) because, just after the ice melting, the two surfaces are both at zero centigrade degrees."

Q7peF: "Answer (c) because the two ice cubes start from the same temperature."

Q7peG: "Answer (d) because I have never experienced this phenomenon before."

Q7deA: "Answer (a) because the thermal power of the thicker plate is lower."

Q7deB: "Answer (b) because the thinner plate dissipates heat better and more quickly."

Q7deC: "Answer (b) because of thermal conduction, the Fourier law (equation)."

Q7deD: "Answer (b) because of the lower thermal capacity of the thinner plate."

Q7deE: "Answer (b) because the body with lower volume is heated and cooled faster."

Q7deF: "Answer (c) because of the zero law of thermodynamics: both plates will reach the ambient temperature."

Q7exA: "Answer (b) because the thicker plate has more thermal energy."

Q7exB: "Answer (b) because the thicker plate, having a bigger mass, has much more particles with kinetic energy $1 / 2 \mathrm{mv}^{2}=3 / 2 \mathrm{KT}$ to be cooled by the ice cube."

Q7exC: "Answer (b) because, by using the heat definition (formula), we know that in order to change the temperature of a more massive object we need a greater amount of heat."

Q8peA: "Answer (c) because I feel the glass beaker colder.”

Q8peB: "Answer (c) because, even at ambient temperature, glass is always colder than plastic."

Q8deA: "Answer (a) because the glass is a less efficient thermal insulator."

Q8deB: "Answer (b) because, after waiting for many hours, thermal conduction inside the freezer is the same."

Q8deC: "Answer (c) because the glass density is higher than plastic one."

Q8exA: "Answer (b) because the time is enough to reach the thermal equilibrium with the freezer."

Q8exB: "Answer (b) because of the zero law of thermodynamics."

Q9peA: "Yes, because it is the same phenomenon of an open window during the winter."

Q9peB: "Yes, because the metal is a good thermal conductor, as in the case of a spoon in a cup of hot chocolate."

Q9deA: "No, cold does not exist as a form of energy, heat is energy on transit."

Q9deB: "Yes, because of the greater thermal conductivity of the metal nail."

Q9deC: "The metal has a high thermal conductivity and, for the zero law of thermodynamics, the temperature goes from the hand to the ice."
Q9exA: "No, because by following the second principle of thermodynamics, heat naturally flows towards decreasing temperatures."

Q9exB: "No, heat flows from hot to cold bodies."

Q10peA: "No, because the volume of the ocean is very big and, therefore, its temperature cannot change."

Q10peB: "Yes, but the ocean remains at the same temperature because its dimensions are much more bigger."

Q10deA: "Yes, but the sea remains at the same temperature because its mass is much more greater."

Q10deB: "No, because the ocean can be considered a thermal reservoir."

Q10deC: "The temperature of the ocean changes in a very little volume around the hot rock only. Then the system will reach back its initial temperature."

Q10deD: "Sure, because the temperature is an intensive quantity."

Q10exA: "Yes, but the equilibrium temperature will be very close to that of the ocean because the heating process depends on both the temperature difference and the mass, which is very big in the case of the sea."

Q10exB: "Yes. The equilibrium temperature of the system can be predicted by using the following formula, in which we may assume as infinite the mass of the ocean and find an equilibrium temperature essentially equal to that of the ocean."

Q11peA: "Answer (a) because the cool body warms more slowly in case of blowing air at ambient temperature."

Q11peB: "Answer (b) because the fan removes the cold air in contact with the object."

Q11deA: "Answer (b) because of the greater energy exchange."

Q11exA: "Answer (b) because forced convention accelerates heat exchange."

Q12peA: "Answer (c) because I have never experienced this phenomenon before."

Q12peB: "Answer (b) because the object is in vacuum, not in air, which is a conductor."

Q12deA: "Answer (a) because of the cooling by conduction through the supporters of the object."

Q12exA: "Answer (a) because heat flows by radiation from the hot body to the container."

Q13peA: "The room with the lower-positioned window should be fresher because I experienced this phenomenon in my house."

Q13deA: "The room with the higher-positioned window should be fresher because the heat in a room tends to move upwards and gets out of the room more easily."

Q13deB: "By assuming the same amount of radiation passing through the windows, the two rooms are equally heated."

Q13exA: "Convective motions will push the hot air upwards in the room and the higher-positioned window will facilitate its escape, by letting the room fresher." 
Q13exB: "The room with the higher-positioned window should be fresher because hot air is characterized by a lower density and tends to move upwards and gets out of the room more easily."

Q14peA: "Because the first is the floor where people spend more time."

Q14deA: "Because the second floor is the higher and directly exposed to the Sun."

Q14deB: "Because the central floor is more insulated and heat remains trapped."

Q14deC: "Greater air pressure at the same volume, therefore higher temperature (perfect gas formula)."

Q14exA: "Since the first floor has an exposed surface lower than that of the second one, the first floor can be the warmest only in the case of an external temperature lower than that of the inside."

Q14exB: "The situation described in the text should correspond to a winter season, in which much more cold air, at higher density, is present at the ground floor and the second floor exchanges more heat with the colder exterior because of a greater exposure surface."

Q15peA: "Because heat tends to move upwards."

Q15deA: "Because the highest floor is more exposed to solar radiation"

Q15deB: "Because hot air tends to move upwards."

Q15exA: "Because of both greater irradiated surface and internal convection."
[1] National Academy of Engineering (NAE), Grand Challenges for Engineering (The National Academies Press, Washington, DC, 2010).

[2] National Academy of Engineering (NAE), Frontiers of Engineering 2011 (The National Academies Press Washington, DC, 2012).

[3] D. Q. Nguyen, The essential skills and attributes of an engineer: A comparative study of academics, industry personnel and engineering students, Glob. J. Eng. Educ. 2, 65 (1998), http://citeseerx.ist.psu.edu/viewdoc/ download?doi=10.1.1.124.1502\&rep=rep1\&type=pdf.

[4] National Academy of Engineering (NAE), The Engineer of 2020: Visions of Engineering in the New Century (The National Academies Press, Washington, DC, 2004).

[5] M. Borrego and J. Bernhard, The emergence of engineering education research as an international connected field of inquiry, J. Eng. Educ. 100, 14 (2011).

[6] P. G. Jasien and G. E. Oberem, Understanding of elementary concepts in heat and temperature among college students and K-12 teachers, J. Chem. Educ. 79, 889 (2002).

[7] R. A. Streveler, B. M. Olds, R. L. Miller, and M. A. Nelson, Using a Delphy study to identify the most difficult concepts for students to master in thermal and transport science, in Proceedings of the ASEE Annual Conference, Nashville, Tennessee, 2003, http://2020engineer.iss.utep .edu/world/Research\%20Literature/ ASEE03_delphi_paper.pdf.

[8] R. A. Streveler, T. A. Litzinger, R. L. Miller, and P. S. Steif, Learning conceptual knowledge in the engineering science: Overview and future research directions, J. Eng. Educ. 97, 279 (2008).

[9] A. H. Shoenfeld, Learning to think mathematically: Problem solving, metacognition, and sense making in mathematics, in Handbook of Research on Mathematics Teaching and Learning, edited by D. Grouws (MacMillan, New York, 1992), p. 334.

[10] B. K. Hofer and P. R. Pintrich, The development of epistemological theories: Beliefs about knowledge and knowing and their relation to learning, Rev. Educ. Res. 67, 88 (1997).

[11] B. K. Hofer and P. R. Pintrich, Personal Epistemology: The Psychology of Beliefs about Knowledge and Knowing (Lawrence Erlbaum, Mahwah, NJ, 2002).

[12] D. Hammer and A. Elby, Tapping epistemological resources for learning physics, J. Learn. Sci. 12, 53 (2003).

[13] E. F. Redish and K. A. Smith, Looking beyond content: Skill development for engineers, J. Eng. Educ. 97, 295 (2008).

[14] A. Gupta and A. Elby, Beyond epistemological deficits: Dynamic explanations of engineering students' difficulties with mathematical sense-making, Int. J. Sci. Educ. 33, 2463 (2011).

[15] E. Kuo, M. M. Hull, A. Gupta, and A. Elby, How students blend conceptual and formal mathematical reasoning in solving physics problems, Sci. Educ. 97, 32 (2013).

[16] American Association for the Advancement of Science (AAAS), Benchmarks for Science Literacy (Oxford University Press, New York, 1993), Project 2061.

[17] National Research Council (NRC), National Science Education Standards, National Committee for Science Education Standards and Assessment (The National Academy Press, Washington, DC, 1996).

[18] National Research Council (NRC), Inquiry and the National Science Education Standards: A Guide for Teaching and Learning (The National Academies Press, Washington, DC, 2000).

[19] M. Rocard, P. Csermely, D. Jorde, D. Lenzen, H. WalbergHenriksson, and V. Hemmo, Science Education now: A renewed pedagogy for the future of Europe, EU Research Report, 2007.

[20] National Research Council (NRC), Discipline-Based Education Research: Understanding and Improving Learning in Undergraduate Science and Engineering (The National Academies Press, Washington, DC, 2011).

[21] National Research Council (NRC), A Framework for K-12 Science Education: Practices, Crosscutting Concepts, and 
Core Ideas (The National Academies Press, Washington, DC, 2012).

[22] D. Llewellyn, Inquiry Within: Implementing Inquiry-based Science Standards (Corwin Press, Inc., Thousand Oaks, CA, 2002).

[23] R. Gras, F. Suzuki, F. Guillet, and F. Spagnolo, Statistical Implicative Analysis: Theory and Applications (Springer, New York, 2008).

[24] D. Hammer and A. Elby, in Personal Epistemology: The Psychology of Beliefs about Knowledge and Knowing, edited by B.K. Hofer and P. R. Pintrich (Lawrence Erlbaum, Mahwah, NJ, 2002), p. 169.

[25] S. Rosenberg, D. Hammer, and J. Phelan, Multiple epistemological coherences in an eighth-grade discussion of the rock cycle, J. Learn. Sci. 15, 261 (2006).

[26] T. J. Bing and E. F. Redish, Analyzing problem solving using math in physics: Epistemological framing via warrants, Phys. Rev. ST Phys. Educ. Res. 5, 020108 (2009).

[27] PROFILES (http://www.profiles-project.eu/); PATHWAY (http:// www.pathway-project.eu/); PRIMAS (http://www.primasproject.eu/); FIBONACCI (http://www.fibonacci-project.eu/); ESTABLISH (http://www.establish-fp7.eu/); SAILS (http:// www.sails-project.eu/).

[28] C. Bolte, J. Holbrook, and F. Rauch, Inquiry-based science education in Europe: Reflections from the PROFILES project, in Proceedings of the First International PROFILES Conference, Berlin, Germany, 2012, http:// www.profiles-project.eu/res/Conference_2012/PROFILES_ Book_final_October2012.pdf?1351682282.

[29] National Academy of Engineering and National Research Council (NAE \& NRC), Engineering in K-12 Education: Understanding the Status and Improving the Prospect, edited by L. Katehi, G. Pearson, and M. Feder (The National Academies Press, Washington, DC, 2009).

[30] J. J. Schwab, The teaching of science as inquiry, in The Teaching of Science, edited by J. J. Schwab and P. F. Brandwein (Harvard University Press, Cambridge, MA, 1962), p. 3.

[31] M. D. Herron, The nature of scientific enquiry, School Rev. 79, 171 (1971).

[32] H. Banchi and R. Bell, The many levels of inquiry, Sci. Child. 46, 26 (2008), http://www.miseagrant.umich.edu/ lessons/files/2013/05/The-Many-Levels-of-Inquiry-NSTAarticle.pdf.

[33] R. W. Bybee, An instructional model for science education, in Developing Biological Literacy (Biological Sciences Curriculum Study, Colorado Springs, CO, 1993).

[34] M. A. Mooney and T. A. Laubach, Adventure engineering: A design centered, inquiry based approach to middle grade science and mathematics education, J. Eng. Educ. 91, 309 (2002).

[35] B. A. Crawford, Learning to teach science as inquiry in the rough and tumble of practice, J. Res. Sci. Teach. 44, 613 (2007).

[36] D. D. Minner, A. J. Levy, and J. Century, Inquiry-based science instruction-What is it and does it matter? Results from a research synthesis years 1984 to 2002, J. Res. Sci. Teach. 47, 474 (2010).

[37] K. Pyatt and R. Sims, Virtual and physical experimentation in inquiry-based science labs: Attitudes, performance, and access, J. Sci. Educ. Technol. 21, 133 (2012).
[38] C. V. Redelman, M. W. Hawkins, F. R. Drumwright, B. Ransdell, K. Marrs, and G. G. Anderson, Inquiry-based examination of chemical disruption of bacterial biofilms, Biochem. Mol. Biol. Educ. 40, 191 (2012).

[39] B. A. Lindsey, L. Hsu, H. Sadaghiani, J. W. Taylor, and K. Cummings, Positive attitudinal shifts with the Physics by Inquiry Curriculum across multiple implementations, Phys. Rev. ST Phys. Educ. Res. 8, 010102 (2012).

[40] L. C. McDermott and Physics Education Group at the University of Washington, Physics by Inquiry (John Wiley \& Sons, New York, 1996).

[41] K. Nottis, M. Prince, and M. Vigeant, Building an understanding of heat transfer concepts in undergraduate chemical engineering courses, US-China Educ. Rev. 7, 1 (2010), http://files.eric.ed.gov/fulltext/ED511218.pdf.

[42] J. Ogborn, Curriculum development in physics: Not quite so fast!, Sci. Ed. 3, 3 (2012), http://www.scied.cz/ FileDownload.aspx?FileID=439.

[43] R. Millar, Rethinking science education: Meeting the challenge of "science for all," Sch. Sci. Rev. 93, 21 (2012), http://www.ase.org.uk/journals/school-sciencereview/2012/06/345/.

[44] N. Trautmann, J. MaKinster, and L. Avery, What makes inquiry so hard? (and why is it worth it), in Proceedings of the Annual Meeting of the National Association for Research in Science Teaching, Vancouver, BC, Canada, 2004, http://ei.cornell.edu/pubs/NARST_04_CSIP.pdf.

[45] C. Quintana, X. Zhang, and J. Krajcik, A framework for supporting meta cognitive aspects of online inquiry through software-based scaffolding, Educ. Psychol. 40, 235 (2005).

[46] C. A. R. Berg, V. C. B. Bergendahl, and B. K. S. Lundberg, Benefiting from an open-ended experiment? A comparison of attitudes to, and outcomes of, an expository versus an open-inquiry version of the same experiment, Int. J. Sci. Educ. 25, 351 (2003).

[47] C. Yen and S. Huang, Authentic learning about tree frogs by preservice biology teachers in open-inquiry research settings, in Proceedings of the National Science Council, Republic of China, ROC(D) (Taiwan National Science Council, Taipei, 2001), Vol. 11, p. 1.

[48] R. A. Krystyniak and H. W. Heikkinen, Analysis of verbal interactions during an extended, open-inquiry general chemistry laboratory investigation, J. Res. Sci. Teach. 44, 1160 (2007).

[49] M. Zion, M. Slezak, D. Shapira, E. Link, N. Bashan, M. Brumer, T. Orian, R. Nussinowitz, D. Court, B. Agrest, R. Mendelovici, and N. Valanides, Dynamic, open inquiry in biology learning, Sci. Educ. 88, 728 (2004).

[50] I. Sadeh and M. Zion, The development of dynamic inquiry performances within an open inquiry setting: A comparison to guided inquiry setting, J. Res. Sci. Teach. 46, 1137 (2009).

[51] C. A. Chinn and B. A. Malhotra, Epistemologically authentic inquiry in schools: A theoretical framework for evaluating inquiry tasks, Sci. Educ. 86, 175 (2002).

[52] F. Abd-El-Khalick, Embedding nature of science instruction in preservice elementary science, J. Sci. Teach. Educ. 12, 215 (2001). 
[53] R. S. Schwartz, N. G. Lederman, and B. A. Crawford, Developing views of nature of science in an authentic context: An explicit approach to bridging the gap between nature of science and scientific inquiry, Sci. Educ. 88, 610 (2004).

[54] L. Flick and N. G. Lederman, Scientific inquiry and nature of science, in Contemporary Trends and Issues in Science Education, edited by L. Flick and N.G. Lederman (Kluwer Academic Publishers, The Netherlands, 2004), Vol. 25, ISBN 978-1-4020-2671-3.

[55] C. K. Capps and B. A. Crawford, Inquiry-based instruction and teaching about nature of science: Are they happening? J. Sci. Teach. Educ. 24, 497 (2013).

[56] K. Hogan, Relating students' personal frameworks for science learning to their cognition in collaborative contexts, Sci. Educ. 83, 1 (1999).

[57] N. R. Pearsall, J. E. J. Skipper, and J. J. Mintzes, Knowledge restructuring in the life sciences: A longitudinal study of conceptual change in biology, Sci. Educ. 81, 193 (1997).

[58] C.-C. Tsai, An analysis of scientific epistemological beliefs and learning orientations of Taiwanese eighth graders, Sci. Educ. 82, 473 (1998).

[59] C.-C. Tsai, Laboratory exercises help me memorize the scientific truths: A study of eight graders' scientific epistemological views and learning in laboratory activities, Sci. Educ. 83, 654 (1999).

[60] D. Hammer, Epistemological beliefs in introductory physics, Cognit. Instr. 12, 151 (1994).

[61] T. J. Bing and E. F. Redish, Analyzing problem solving using math in physics: Epistemological framing via warrants, Phys. Rev. ST Phys. Educ. Res. 5, 020108 (2009).

[62] B. K. Hofer and P. R. Pintrich, The development of epistemological theories: Beliefs about knowledge and knowing and their relation to learning, Rev. Educ. Res. 67, 88 (1997).

[63] L. Lising and A. Elby, The impact of epistemology on learning: A case study from introductory physics, Am. J. Phys. 73, 372 (2005).

[64] M. T. H. Chi, P. J. Feltovich, and R. Glaser, Categorization and representation of physics problems by experts and novices, Cogn. Sci. 5, 121 (1981).

[65] E. F. Redish, J. M. Saul, and R. N. Steinberg, Student expectations in introductory physics, Am. J. Phys. 66, 212 (1998).

[66] A. H. Schoenfeld, Learning to think mathematically: Problem solving, metacognition, and sense-making in mathematics, in Handbook for Research on Mathematics Teaching and Learning, edited by D. Grouws (MacMillan, New York, 1992), p. 334.

[67] E. F. Redish and A. Gupta, Making meaning with math in physics: A semantic analysis, in Proceedings of the Groupe International de Recherche sur l'Enseignement de la Physique (GIREP), Leicester, U.K., 2010, http:// www2.physics.umd.edu/ redish/Papers/ GIREP2009_16_Redish.pdf.

[68] W. A. Sandoval, Understanding students' practical epistemologies and their influence on learning through inquiry, Sci. Educ. 89, 634 (2005).
[69] A. Gupta, B. A. Danielak, and A. Elby, Understanding students' difficulties in terms of coupled epistemological and affective dynamics, in ASEE/IEEE 2010 Frontiers in Education Conference Proceedings (IEEE, Los Alamitos, CA, 2010), retrieved from http://arxiv.org/abs/1003.4238.

[70] R. T. White and R. F. Gunstone, Metalearning and conceptual change, Int. J. Sci. Educ. 11, 577 (1989).

[71] S. Vosniadou, Capturing and modeling the process of conceptual change, in Special Issue on Conceptual Change, Learning and Instruction, edited by S. Vosniadou [Learn. Instr. 4, 45 (1994)].

[72] D. E. Meltzer, Investigation of students' reasoning regarding heat, work, and the first law of thermodynamics in an introductory calculus-based general physics course, Am. J. Phys. 72, 1432 (2004).

[73] A. Tiberghien, Quelques éléments sur l'evolution de la recherche en didactique de la physique, Rev. Fr. Pedagog. 72, 71 (1985), http://www.jstor.org/stable/41163304.

[74] E. E. Clough and R. Driver, A study of consistency in the use of students' conceptual frameworks across different task contexts, Sci. Educ. 70, 473 (1986).

[75] S. Kesidou, R. Duit, and S. Glynn, Conceptual development in physics: students understanding of heat, in Learning Science in the Schools: Research Reforming Practice, edited by S. Glynn and R. Duit (Lawrence Erlbaum, Mahwah, NJ, 1995).

[76] A. G. Harrison, D. J. Grayson, and D. F. Treagust, Investigating a grade 11 student's evolving conceptions of heat and temperature, J. Res. Sci. Teach. 36, 55 (1999).

[77] M. T. H. Chi, Common-sense conceptions of emergent processes: Why some misconceptions are robust, J. Learn. Sci. 14, 161 (2005).

[78] R. L. Miller, R. A. Streveler, D. Yang, and A. I. SantiagoRomán, Identifying and repairing student misconceptions in thermal and transport science: Concept inventories and schema training studies, Chem. Eng. Educ. 45, 203 (2011), http://www.thermalinventory.com/images/Papers/ Miller_CEE_TTCI_schema_summer_2011.pdf.

[79] M. Prince, M. Vigeant, and K. Nottis, Development of the heat and energy concept inventory: Preliminary results on the prevalence and persistence of engineering students' misconceptions, J. Eng. Educ. 101, 412 (2012).

[80] K. A. Ericsson, N. Charness, P. J. Feltovich, and R. R. Hoffman, The Cambridge Handbook of Expertise and Expert Performance (Cambridge University Press, New York, 2006).

[81] G. Brousseau, Theory of Didactical Situations in Mathematics, edited by M. Cooper, N. Balacheff, R. Sutherland, and V. Warfield (Kluwer Academic, Dordrecht, 1997).

[82] M. P. Jensen, Questionnaire validation: A brief guide for readers of the research literature, Clin. J. Pain 19, 345 (2003).

[83] C. Fazio and F. Spagnolo, Conceptions on modeling processes in Italian high school prospective mathematics and physics teachers, S. Afr. J. Educ. 28, 469 (2008), http:// www.ajol.info/index.php/saje/article/view/25169.

[84] C. Fazio, B. Di Paola, and I. Guastella, Prospective elementary teachers' perceptions of the processes of 
modeling: A case study, Phys. Rev. ST Phys. Educ. Res. 8, 010110 (2012).

[85] C. Fazio, O. R. Battaglia, and B. Di Paola, Investigating the quality of mental models deployed by undergraduate engineering students in creating explanations: The case of thermally activated phenomena, Phys. Rev. ST Phys. Educ. Res. 9, 020101 (2013)

[86] F. Marton, Describing and improving learning, in Learning Strategies and Learning Styles, edited by R. R. Schmeck (Plenum Press, New York, 1988) p. 53.

[87] F. Marton and S. Booth, Learning and Awareness (Lawrence Erlbaum, Mahwah, NJ 1997).

[88] J. T. E. Richardson, The concepts and methods of phenomenographic research, Rev. Educ. Res. 69, 53 (1999).

[89] I. C. Lerman, Classification et Analyse Ordinale Des Données (Dunod, Paris, 1981).

[90] I. C. Lerman, R. Gras, and H. Rostam, Elaboration et évaluation d'un indice d'implication pour des données binaires I, Math. Sci. Hum. 74, 5 (1981); Elaboration et évaluation d'un indice d'implication pour des données binaires II, Math. Sci. Hum. 75, 5 (1981).
[91] A. D. Gordon, Classification (Chapman \& Hall, London, England, 1999), 2nd ed.

[92] A. Fernàndez and S. Gòmez, Solving non-uniqueness in agglomerative hierarchical clustering using multidendrograms, J. Classif. 25, 43 (2008).

[93] F. Spagnolo, La modélisation dans la recherche en didactiques des mathématiques: Les obstacles épistémologiques, Rech. Didact. Math. 26, 337 (2006), http://rdm .penseesauvage.com/La-modelisation-dans-la-recherche .html.

[94] R. Couturier, R. Gras, and F. Guillet, Reducing the number of variables using implicative analysis, in Classification, Clustering, and Data Mining Applications: Proceedings of the Meeting of the International Federation of Classification Societies (IFCS 2004) (Springer-Verlag, Berlin, 2004), p. 277.

[95] A. Markos, G. Menexes, and I. Papadimitriou, The CHIC analysis software v1.0., in Classification as a Tool for Research: Proceedings of the 11th International Federation of Classification Conference, edited by H. LoracekJunge and C. Weihs (Springer, Berlin, 2010), p. 409. 